\title{
An individual-level perspective on intrapreneurship: a review and ways forward
}

\author{
Christine Blanka ${ }^{1}$ (D)
}

Received: 25 February 2017 / Accepted: 16 January 2018 / Published online: 9 February 2018 (C) The Author(s) 2018. This article is an open access publication

\begin{abstract}
Intrapreneurship as a sub-field of entrepreneurship has increased in importance. Due to the crucial role of entrepreneurial employees with regard to innovation and competitive advantage, research has increased and various concepts have emerged. Despite the growing interest in the field, intrapreneurship is still lacking a clear classification of the related concepts as research has thus far been based on diverse theoretical approaches. Indeed, contributions in the field are fragmented, using various definitions. There is no systematic review providing an overview of the field. By distinguishing between corporate entrepreneurship, entrepreneurial orientation and intrapreneurship, this paper clearly positions intrapreneurship as individual-level concept. Most prior research has been done at the organizational level, focusing on concepts such as corporate entrepreneurship, but research concentrating on individual intrapreneurial employees is rare. Therefore, this paper closes the gap by performing a systematic literature review and using a narrow focus to present the current state of research with regard to the individual-level perspective on intrapreneurship. The results of the review make it possible to identify five different research streams based on the analytical levels applied. The research streams examined used various lenses and cover business, technological and academic contexts. In a final step, the findings and possible research agendas are integrated in a model that serves as the basis for future research initiatives. Hence the paper offers the possibility of a clearer justification for future research and is a first step towards a holistic research model related to intrapreneurship.
\end{abstract}

Keywords Intrapreneurship · Intrapreneurial behaviour · Entrepreneurial employees · Corporate entrepreneurship $\cdot$ Systematic literature review

Christine Blanka

christine.blanka@jku.at

1 Institute for Entrepreneurship and Organizational Development, Johannes Kepler University

Linz, Altenberger Straße 69, 4040 Linz, Austria 


\section{JEL Classification L26}

\section{Introduction}

Entrepreneurship in existing organizations has gained relevance in research as well as in practice. Due to the increasingly turbulent and competitive economic environment, firms have been looking for ways of managing innovation and generating competitive advantage. In this regard, entrepreneurial employees have been placed at the centre, as it has been emphasized that innovative employee behaviour leads to firm growth and strategic renewal (Veenker et al. 2008). Based on this assumption, various studies have been developed, focusing on different perspectives (individual-, team- and organizational level) and diverse theoretical foundations. The outcome of this is a new sub-field in entrepreneurship research, called intrapreneurship (Antoncic and Hisrich 2003). Due to the lack of a consistent definition of the concept of intrapreneurship (Åmo and Kolvereid 2005; Christensen 2005; Menzel et al. 2007), as well as different theoretical perspectives, intrapreneurship is a broad concept addressed in various research areas.

In this context, intrapreneurship is an emerging field in research and entrepreneurial employees especially and their skills and competencies gain in importance. Human capital plays a significant role when it comes to the success of ventures (e.g. Parker 2011). Intrapreneurs, defined as entrepreneurial-thinking people within existing firms, are crucial as they think across the boundaries of organizational units (Pinchot 1985). Therefore, these intrapreneurial employees are the foundation for innovation and the subsequent competitive advantage of firms (Guerrero and PeñaLegazkue 2013).

Depending on the varying theoretical approaches, related concepts such as entrepreneurial orientation (Anderson and Covin 2014; Covin and Wales 2012), corporate entrepreneurship (Dess et al. 2003; Ireland et al. 2009) and corporate venturing (Antoncic and Hisrich 2003) have emerged. Moreover, similar but nevertheless different concepts and synonyms have developed, leading to further confusion in the field of intrapreneurship (e.g. Edú Valsania et al. 2016).

Responding to the need for clarification of the intrapreneurship concept, this paper seeks to examine the emphasis in intrapreneurship research and provides an overview of relevant issues in the field. Antoncic and Hisrich (2003) have already tried to clarify the concept of entrepreneurship within existing organizations and have provided an overview differentiating it from similar concepts, such as diversification strategy, organizational learning and organizational innovation. Furthermore, they point out the different dimensions of entrepreneurship and describe an eight-dimensional concept for organizational-level entrepreneurship. Although the authors used the term intrapreneurship in their research, their focus was not on the individual entrepreneurial employees but on organizations as a whole. The fact that their research was based on literature in the fields of management, innovation, strategy and entrepreneurial orientation further underlines that their focus was on the firm level than on the individual level. 
In contrast, the aim of this paper is to identify the current research focus and possible research gaps in the intrapreneurship field at the individual level. Organizational-level concepts such as corporate entrepreneurship have already been investigated and results concerning the effects on a firm's success are available. However, research providing an overview of individual-level intrapreneurship is rare, leading to the need for a research focus at this level. Based on the idea that entrepreneurial employees and their human capital are key to the success of ventures, a closer look is taken at intrapreneurs. To complement the organizational perspective of Antoncic and Hisrich (2003), the paper performs a systematic literature review and presents the findings focusing on intrapreneurship at the individual level. The results make it possible to present a research map and point out different research streams, as well as a future research agenda.

The paper accesses the field from the individual level perspective and hence contributes in several ways to the current development of the intrapreneurship field. As intrapreneurship is based on various theoretical concepts and perspectives, the contributions in the field are fragmented and employ various definitions (e.g. Turro et al. 2016). Despite the emergence of intrapreneurship research over recent years, there has as yet been no systematic review showing a detailed overview of the field. Therefore, this paper aims to close this research gap by performing a systematic literature review and presenting the current state of research. In addition, the paper answers the call for a clearer picture of the intrapreneurship concept by using a narrow focus and clearly distinguishing organizational- and individual-level concepts related to intrapreneurship. Hence, the contributions are threefold. First, as proposed by Åmo (2010), the paper distinguishes the concepts of corporate entrepreneurship, entrepreneurial orientation and intrapreneurship by mapping the literature. Furthermore, by clarifying the diverse concepts and their cutting points, it enables the identification of interesting gaps and shows the distinct position of intrapreneurship as an individual-level concept in the field. Second, with regard to current knowledge, it is the first paper to examine the intrapreneurship literature of the last few years by conducting a systematic literature review. By concentrating on the individual-level perspective, the review is restricted to a narrow focus which has been almost neglected in research as a separate area until now. The research performed in this paper takes a closer look at intrapreneurial individuals and therefore provides a knowledge base in this research field. Third, it contributes to the identification of the different streams in intrapreneurship research by shaping five different clusters dealing with various analytical levels. Therefore, the review tries to differentiate the various related emphases in individual-level intrapreneurship and points out paths for future holistic research approaches in this field.

The paper is structured as follows. The next section provides the theoretical foundations for this research and differentiates individual-level intrapreneurship from other concepts of entrepreneurship within firms. Section 3 introduces the review approach and the sample of journal articles included in the systematic literature review. Then, the findings of the research are presented by restructuring the intrapreneurship literature into different research streams in Sect. 4. In the next section, the paper discusses major findings and the research gaps identified. Furthermore, based on the review results, implications for theory are drawn and an outlook is provided 
on future research in the field of intrapreneurship. The paper concludes with implications for practice, as well as limitations.

\section{Theoretical background}

\subsection{Conceptualizing entrepreneurship within firms}

Changes in the global economy have forced existing firms to put a particular focus on being innovative and moreover gaining competitive advantage (Kuratko and Audretsch 2013). Therefore, the research in the entrepreneurship field has clearly expanded by focusing not only on new venture creation and entrepreneurs, but also on the value of entrepreneurship within existing organizations (Antoncic and Hisrich 2003). The basic assumption is that innovative employee behaviour influences the firm's performance by facilitating strategic renewal and access to new resources and skills (Dess et al. 2003; Kuratko and Audretsch 2013; Veenker et al. 2008). Although entrepreneurs also show innovative activities, research clearly distinguishes entrepreneurs from entrepreneurial employees. Entrepreneurial employees have been defined as intrapreneurs based on the work of Pinchot (1985). He introduced the term "intrapreneur" as a combination of "intracorporate" and "entrepreneur" and stated that intrapreneurs "closely resemble entrepreneurs [...] who turn ideas into realities inside an organisation" (Pinchot and Pellman 1999, p. 16). Three main differences in particular are highlighted between intrapreneurs and entrepreneurs: intrapreneurs are able to use the existing resources of the company, they operate within organizations and they work within organizations that already have their own policies and bureaucracy (Baruah and Ward 2015; Camelo-Ordaz et al. 2012).

Shortly after its inception, research on entrepreneurship within firms emerged and focused on different levels of examination. Since this new field of research focuses on entrepreneurship in organizations, it is not surprising that much of the work conducted in the last decades has been established at the organizational level (Covin and Slevin 1991). Research based on this perspective examined organizational factors that influence employees' entrepreneurial behaviour and the effect of this on company performance (Camelo-Ordaz et al. 2012; Menzel et al. 2007). Other research focused on the opposite perspective and was centred on the individual. Hence the individual characteristics of intrapreneurs (e.g. Martiarena 2013) as well as the determinants of employees' entrepreneurial behaviour within firms have been examined (e.g. Douglas and Fitzsimmons 2013). Based on these two main perspectives, researchers indicated the need for a third perspective- the team-level perspectivein studies of employee entrepreneurship (Gapp and Fisher 2007). Research focusing on this level is scarce and only a few authors deal with intrapreneurial teams, e.g. their influence on the service and product development process (Gapp and Fisher 2007), or how intrapreneurial teams operate in various business contexts (Iacobucci and Rosa 2010).

As result of these three perspectives, different concepts dealing with entrepreneurship in firms were established. Approaches such as corporate entrepreneurship, corporate venturing, entrepreneurial orientation and intrapreneurship emerged, 
leading to some confusion as a clear classification is missing (Christensen 2005; Urbano and Turro 2013). Antoncic and Hisrich (2003) tried to provide an overview of the concepts and identified two streams of research at the organizational level. As a first stream, the authors pointed to the entrepreneurial orientation (EO) approach, which is based on the idea that innovation is a dimension of strategy making (Wales 2015). Hence, EO is defined as a firm-level construct (Anderson and Covin 2014), which is observable through EO on the part of the entire organization and a collection of organizational behaviours (Covin and Wales 2012). The construct developed through a series of studies and identifies an entrepreneurial firm as "one that engages in product-market innovation, undertakes somewhat risky ventures, and is first to come up with 'proactive' innovations" (Miller 1983, p. 771). Based on three dimensions - innovativeness, risk taking and proactiveness-a basic strategic orientation was established to measure the EO of firms (Bouchard and Basso 2011; Covin and Slevin 1991). Further research added two dimensions-autonomy and competitive aggressiveness - and established a five-dimensional construct (Lumpkin and Dess 1996; Wales 2015). Also based on the organizational level is the second stream identified by Antoncic and Hisrich (2003), which points to the fostering of innovation and opportunity exploitation within a firm (Rigtering and Weitzel 2013). The so-called corporate entrepreneurship (CE) approach (e.g. Dess et al. 2003; Ireland et al. 2009) is similar to the EO approach, but distinguishes clearly two main streams. Corporate entrepreneurship can result either in corporate venturing $(C V)$ and the creation of new business or the renewal of an existing organization. Later research also distinguishes these two characteristics and labels CV on the one hand and strategic entrepreneurship (dealing simultaneously with the topics of opportunity seeking and advantage seeking) on the other hand, under the banner of CE (Kuratko and Audretsch 2013).

Researchers in this specific field of entrepreneurship have increasingly differentiated between an organizational- and individual-level perspective (Moriano et al. 2014; Wakkee et al. 2010). Prior research has highlighted that CE and the intrapreneurship concept are closely linked, but are nevertheless not the same (Åmo 2010). In recent research, one characteristic in particular has gained recognition in differentiating between $\mathrm{CE}$ and intrapreneurship: CE can be seen as innovation process initiated from the top down within an organization, whereas intrapreneurship can be seen as bottom-up approach related to the intrapreneurial behaviour of employees (Åmo and Kolvereid 2005; Rigtering and Weitzel 2013; Sinha and Srivastava 2013). This clearly shows the different perspectives and the need for a clear classification between CE and intrapreneurship.

\subsection{Intrapreneurship}

As stated, the concepts of intrapreneurship and CE are closely linked to each other. Various researchers in this field have provided fruitful insights into how to differentiate the two approaches. The intrapreneurship concept is based on the idea that valuable human capital resides in entrepreneurial employees within existing organizations (Guerrero and Peña-Legazkue 2013; Parker 2011). In particular, the characteristics 
of human capital, observable through intrapreneurial behaviour, provide a bridge between intrapreneurship and $\mathrm{CE}$, either in terms of $\mathrm{CE}$ as a desired result from the firm's top level or in terms of intrapreneurship as self-determined behaviour of employees (Amo and Kolvereid 2005). It is also stated that CE does not automatically result in intrapreneurship behaviour as "the decision to opt for intrapreneurship remains an individual and personal decision" (Rigtering and Weitzel 2013, p. 342). Based on the aforementioned approaches and prior research, this paper tries to differentiate clearly the intrapreneurship concept as being at the individual level from the related concepts by mapping the diverging research approaches. Therefore $\mathrm{CE}$ and EO are categorized as organizational-level approaches and distinct from one another, as supposed by Antoncic and Hisrich (2003).

To sum up prior research and create an initial starting point for the systematic literature review, the paper maps the literature (Fig. 1) based on two dimensions: the level of perspective (organizational or individual) and the context of either an existing organization or new venture creation. Both EO and CE are categorized at the organizational level. Based on the assumption that these two constructs are related (Bouchard and Basso 2011) but not the same, they are separated. EO, mainly focusing on firms' general strategic orientation towards entrepreneurship (Wales 2015), is mapped as approach for existing organizations. In contrast, the CE approach is divided into strategic entrepreneurship (referring to existing organizations) and CV (referring to new venture creation). This is also in line with prior work that identifies these two main streams of the CE construct (Antoncic and Hisrich 2003; Kuratko and Audretsch 2013).

The paper clearly categorizes intrapreneurship as an individual-level approach in existing organizations, supported by the definition of the intrapreneur as an employee who "recognizes opportunities and develops innovations from within an existing hierarchy" (Camelo-Ordaz et al. 2012, p. 3). Thus, it can be argued that intrapreneurial behaviour is not possible in $\mathrm{CV}$, as it focuses on the creation of new businesses rather than developing innovations in existing ones. Rather, CV and new

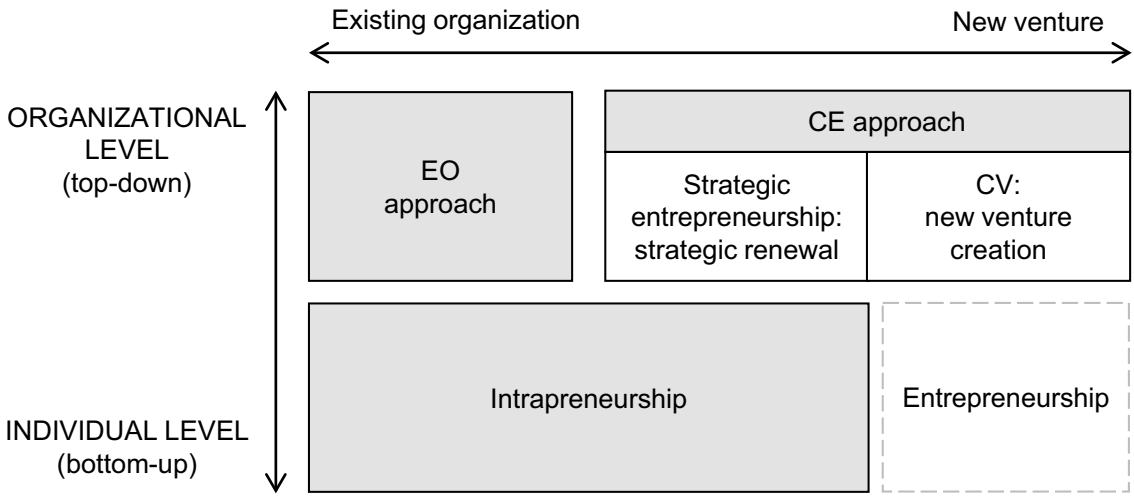

Fig. 1 Mapping research on entrepreneurship within firms. Based on the works of Antoncic and Hisrich (2003), Bouchard and Basso (2011), Kuratko and Audretsch (2013) and Rigtering and Weitzel (2013) 
venture creation are associated with separation from the existing corporate firm and will lead to entrepreneurial tasks with higher risks and responsibilities, as well as the use of own resources. Hence, it is considered that CV will result in entrepreneurial behaviour at the individual level. Prior research has offered the insight that the organizational level (EO and CV) is closely linked to intrapreneurship. EO and CE can be seen as a breeding ground for intrapreneurship and vice versa. Both organizational antecedents and the individual self-determined behaviour of employees are necessary to enable intrapreneurial behaviour within established firms (Amo and Kolvereid 2005).

Based on the literature map in Fig. 1, the paper is positioned in the field of intrapreneurship. As there is existing research on organizational concepts and also reviews on CE and EO are available (e.g. Dess et al. 2003; Kuratko and Audretsch 2013; Wales 2015), this paper focuses on the concept of intrapreneurship as an individual-level approach. By concentrating the review on this specific field, the paper sheds light on intrapreneurial individuals within organizations, constitutes a review of various research efforts on intrapreneurship and creates a knowledge base for future research directions.

\section{Methodology}

\subsection{Review approach}

To investigate the current state of research on individual-level intrapreneurship, a systematic literature review (SLR) was performed. This approach makes it possible to provide an overview of prior research in the field and a holistic perspective on the common knowledge base. Furthermore, the review contributes to the development of the intrapreneurship field by identifying different research streams and illustrating possible future research agendas. A systematic review approach is characterized by thoroughness and rigour, leading to legitimacy and the objectivity of results (Creswell 2009; Jesson et al. 2011; Tranfield et al. 2003). Based on this, the paper follows the suggestion of Tranfield et al. (2003) as a reference framework for conducting an SLR in the field of management and business. Therefore, the research was carried out by adopting the basic guidelines of these authors, dividing the SLR into the following steps: (1) planning the review, (2) conducting the review and (3) reporting and disseminating the review.

As Fig. 2 shows, in a first step the field of research was accessed by gaining an overview of relevant concepts in the field of intrapreneurship. In doing so, the current need for an SLR was identified, as different concepts emerged but a clear classification was missing. The aim was to identify relevant journal articles referring to intrapreneurship as an individual-level concept. The databases Ebsco, Emerald, ScienceDirect, Scopus and Web of Science were used. As intrapreneurship is a subfield of entrepreneurship, in Ebsco four relevant entrepreneurship databases were selected: Business Source Premier, EconLit, Entrepreneurial Studies Source and PsycINFO. To be included in the review, the title, abstract or keywords of an article had to contain the search term "intrapreneur*". As the focus of the SLR was 

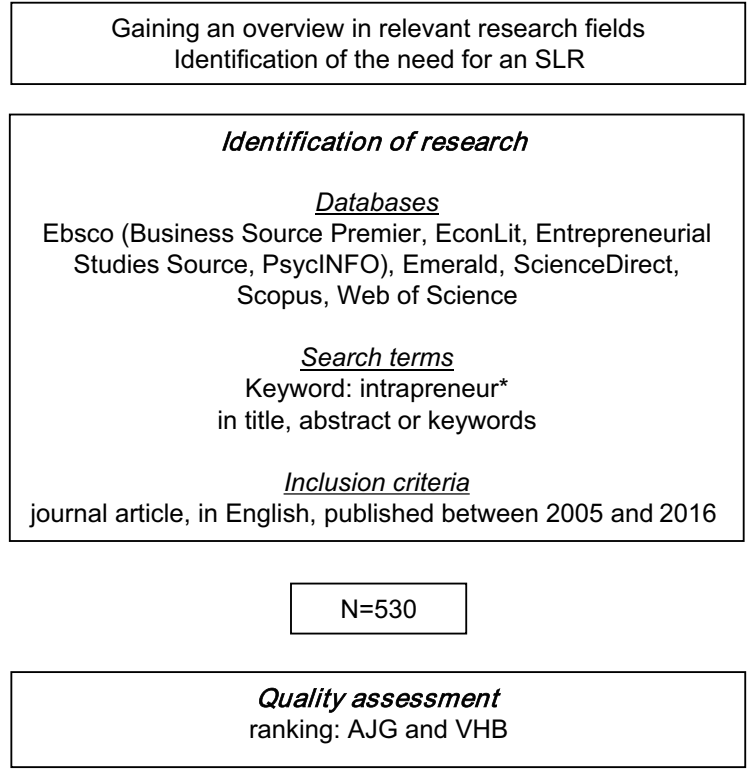

$\mathrm{N}=311$
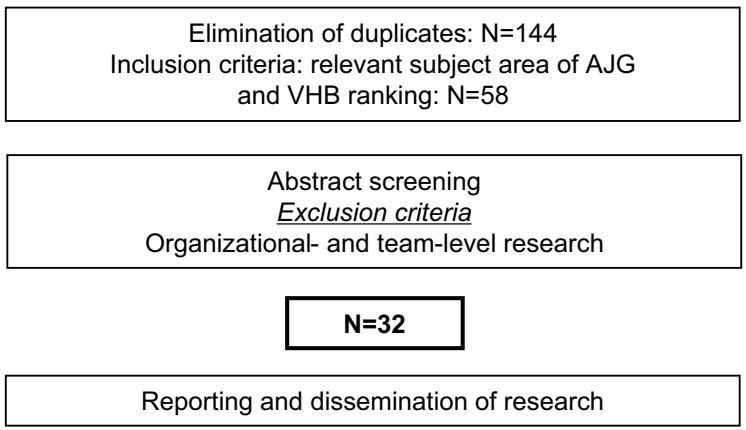

Step 1:

Planning the review

Step 2:

Conducting the review
Step 3:

Reporting and disseminating the review

Fig. 2 Approach for systematic literature review

on the individual level only, the search term was defined in a tight manner based on the definition of intrapreneurship. However, as already stated, researchers in the intrapreneurship field use different terms to describe intrapreneurship as a consistent definition is missing. To take this vagueness into account, the search term had to be included either in the title or abstract or keywords. Thus, research on intrapreneurship using for example the term "corporate entrepreneurship" in the title, but "intrapreneurship" in the abstract or keywords was also included in the search results. The use of an asterisk with the search term ensured that variations (e.g. intrapreneurs, intrapreneurial, intrapreneurship) were included in the results of the literature search. As further inclusion criteria, the type of publication was defined as a journal article, in English and published between 2005 and 2016. 
Using this approach, an initial sample of 530 publications was identified. To ensure the inclusion of high-quality research, a quality assessment was performed and only those publications that were published in journals ranked in the Academic Journal Guide 2015 (AJG) of the Chartered Association of Business Schools or the VHB ranking 2015 (Jourqual 3) of the German Academic Association for Business Research were retained $(\mathrm{N}=311)$. Usually only papers that meet specific ranking criteria (e.g. a ranking $\geq 2$ in the AJG or $\geq \mathrm{C}$ in $\mathrm{VHB}$ ) are kept in review samples to provide a quality threshold. As a result of the narrow focus of the SLR, no further restriction concerning ranking criteria was defined. After the elimination of duplicates, further inclusion criteria were tested to ensure the quality threshold. As intrapreneurship is defined as a sub-field of entrepreneurship, enabling innovation within organizations, only those articles published in journals clustered in the relevant subject areas of AJG (Entrepreneurship and Small Business Management and Innovation) or VHB (Entrepreneurship and Technology, Innovation and Entrepreneurship) were included. Following this limitation, a sample of 58 articles was tested through an abstract-screening process. Based on the narrow definition of intrapreneurship as an individual-level concept, articles applying an organizational- or team-level view were excluded. The final sample of the SLR consisted of 32 articles dealing with intrapreneurship at the individual level.

As a first step, the articles were analysed with regard to their theoretical emphases and the research design applied. In the second step, the articles underwent a detailed content analysis. Relevant issues in the articles were coded and finally different research subjects were identified, synthesized and in a final step re-organized into research streams based on the analytical level applied.

\subsection{An overview of intrapreneurship research}

The sample of the SLR provides insight into the journal classes in which articles concerning intrapreneurship have been published. Different research areas were clustered based on the scope of the journals. The majority of articles appear in journals that focus on Business, Management and Strategy $(\mathrm{N}=12)$, which is not surprising considering the theoretical foundations in management. The 32 articles in the review were published in 21 journals. The journal with the most publications in the thematic field is the International Entrepreneurship and Management Journal, with eight articles in total (see Table 2 in the Appendix). In the period considered, 2005-2016, the number of articles dealing with the topic of intrapreneurship shows a growing trend. In particular, there is a peak in the year 2013, in which nine articles were published. The majority of the articles were published in the research areas of business and management, with only seven articles published in the research areas of innovation and technology.

Although the individual-level perspective was an inclusion criterion, some publications also considered the organizational-level of intrapreneurship (either EO or $\mathrm{CE})$. Regarding the research subject, the sample articles examined factors predicting innovative behaviour, differences between entrepreneurship and intrapreneurship, individual and organizational antecedents of intrapreneurship activities, as well as 
management and leadership. Some authors focused on management themes, such as the role of middle-level managers (Kuratko et al. 2005), coaching by managers and its influence on employees' entrepreneurial self-efficacy (Wakkee et al. 2010) and a processual perspective on intrapreneurship, which considers various actors at different management levels (Belousova and Gailly 2013). Other research has been done examining $\mathrm{CE}$ and its influence on employee behaviour, such as the new roles of engineers as technology intrapreneurs (Menzel et al. 2007), the influence of transformational leadership style on intrapreneurial behaviour (Moriano et al. 2014), organizational antecedents leading to intrapreneurial behaviour and as a further step to intrapreneurship (Rigtering and Weitzel 2013), the influence of intrapreneurial experience on CV (Guerrero and Peña-Legazkue 2013) and bootlegging behaviour of employees to develop ideas not supported by management (Globocnik and Salomo 2015). Three articles also tried to link the organizational and individual levels by developing a combined model of CE and intrapreneurship to predict innovative behaviour (Åmo and Kolvereid 2005), clarifying the intersection of CE and intrapreneurship (Åmo 2010), or developing a link between EO and intrapreneurship (Bouchard and Basso 2011).

In addition to thematic diversity, the articles in the sample also applied different methodological approaches. As shown in Table 3, most authors used a quantitative research design (69\%) to examine intrapreneurship. Only seven articles concerned qualitative research, applying interviews and case studies. Six articles drew on case studies, of which two applied a multiple case study approach. Furthermore, theoretical research work is underrepresented, as only three publications were of a conceptual nature. As is apparent from the sorting of the publications in Table 3 by year of publication, qualitative research designs were mainly employed from 2005 to 2010. From 2010 onward, quantitative research outweighed qualitative and conceptual research, a development that is quite typical of emerging research fields. Most of the quantitative publications were based on large and well-known databases, such as the Global Entrepreneurship Monitor (GEM) survey or the Panel Study of Entrepreneurial Data (PSED). Almost all studies were cross-sectional and only one applied a longitudinal research approach, using interviews to analyse the changed role of engineers and a shift from engineering to entrepreneurial tasks.

The sample contained no article giving an overview of prior research in the field of intrapreneurship or a review of the literature in this field. This further underlines the need for an SLR undertaken to map the literature streams and focus on intrapreneurship research at the individual level.

\section{Results}

\subsection{Theoretical frameworks and perspectives on intrapreneurship}

The sample articles used various theoretical perspectives to investigate individuallevel intrapreneurship. The majority of the journal articles clearly defined a theoretical foundation; indeed most were based on more than one theory. Only two empirical publications lacked a clarification of the theoretical framework. In terms 
of definitions provided in the sample articles, the theoretical concepts of intrapreneurship, CE and EO were the theoretical foundations most mentioned. Pinchot's work (1985), as seminal in the field, was applied in eight contributions focusing on the concept of intrapreneurship, defining intrapreneurs and distinguishing intrapreneurship from other concepts. Besides meeting the inclusion criterion of a focus on individual-level intrapreneurship, some papers also applied organizational-level constructs. Articles based on the CE approach tend to be rooted in the work of Antoncic and Hisrich (2003), as they clarified the intrapreneurship concept and developed a framework to distinguish CE from intrapreneurship, as well as dimensions of organizational-level intrapreneurship. A second source applied to CE research is the work of Kanter (1984). She underlined the relevance of initiatives undertaken by individuals within organizations and stated that $\mathrm{CE}$ should result in innovation behaviour among employees. Articles using the EO framework are based on the idea that EO is an organization-wide strategy for fostering innovation. Covin and Slevin (1991) identified innovativeness, risk taking and proactiveness as dimensions for measuring organizations' EO and hence their work also provides a framework for the sample articles.

Besides the basic theoretical foundations rooted in the related concepts of intrapreneurship, CE and EO, the sample articles applied various lenses and theories to investigate intrapreneurship. Three theories, presented here, were applied most in the journal articles analysed. The Theory of Planned Behaviour (TPB) is well-established in the intention literature and relevant for analysing entrepreneurial intentions (Ajzen 1985, 1991). It is assumed that intentions predict human behaviour and therefore are of high relevance in research. Based on the assumption that attitudes, subjective norms and perceived behavioural control influence intentions, intrapreneurship research has attempted to delineate differences in entrepreneurial versus intrapreneurial intentions (Douglas and Fitzsimmons 2013; Tietz and Parker 2012). By investigating attitudes (e.g. to income and risk), researchers have aimed to shed light on intrapreneurial intentions and factors influencing these. Furthermore, motivation theories are applied in the sample articles to examine motivational factors for engaging in innovative behaviour within established organizations (Bicknell et al. 2010). In addition, different motives, e.g. financial and independence, have been investigated with regard to intrapreneurial intentions. The third theory most used is social learning theory (Bandura 1986), which states that the learning of novel behaviour is a cognitive process embedded in a social context and occurs through observation and imitation of others. The theory suggests that cognition, behaviour and environment are connected in a reciprocal fashion. The construct of "self-efficacy" is part of social learning theory (Bandura 1977) and is defined as a person's perceived ability to show certain behaviours or fulfil certain tasks. Self-efficacy is influenced by skills, their application and the feedback on applying these skills. Therefore self-efficacy is not only the result of performance, but is also the determinant for further and revised performance. In the field of entrepreneurship, the term entrepreneurial self-efficacy (ESE) has been established. The sample articles examined the ESE of employees and its key role in showing innovative behaviour and forming intrapreneurial intentions (Douglas and Fitzsimmons 2013; Globocnik and Salomo 2015; Wakkee et al. 2010). 
In addition to the various theoretical lenses, the researchers also employed different definitions of intrapreneurship. As no common definition exists with regard to the perspective applied to the phenomenon, the journal articles examined specified intrapreneurship differently. Most researchers drew on Pinchot's work (1985) and used well-known criteria to specify the term intrapreneurship. The majority of the research primarily characterized intrapreneurship through its organizational context (22 articles) by defining it as "entrepreneurship within existing organizations", "entrepreneurship in the large organization", "inside an organization", "in-company entrepreneurship" or "entrepreneurial activities within the organizational context". This is in line with Pinchot's argument that the organizational context in particular differentiates entrepreneurship from intrapreneurship. A further criterion is the origin of intrapreneurial initiatives. In this regard, some studies (nine) clearly branded intrapreneurship as "bottom-up", indicating that intrapreneurial activities emerge from entrepreneurial employees themselves. These publications argued that employees play a key role in realizing intrapreneurial initiatives. Other publications (seven) do not use the term "bottom-up" in their definition, but instead underline the relevance of individuals to intrapreneurship. Two publications concretely distinguish intrapreneurship as an "individual-level concept" from CE as an organizational-level concept. A further attribute often used to define intrapreneurship is the (expected) outcome (13 articles). Terms like "innovation", "strategic renewal" and "out-of-thebox thinking" were applied to flag intrapreneurship as behaviour in pursuing new opportunities and competitive advantage. Besides the constituents of these main attributes mentioned above, the authors used different terms for intrapreneurship. Therefore, the result is a puzzle of similar terms and synonyms that lead to the mixing of different theoretical perspectives (e.g. using the term CE to examine individual employee behaviour).

\subsection{Research streams}

The articles in the SLR were organized into different research streams based on the analytical level applied. As Table 1 shows, by clustering, five streams dealing with different perspectives on intrapreneurship research were defined: individual- and organizational-level perspectives, context-oriented research, research focusing on outcomes and studies concentrating on possible promoting factors of intrapreneurship. To cluster the research, both deductive codes (e.g. individual level), based on the theoretical foundations of the studies, and inductive sub-codes (leadership) that emerged from the data were deployed.

In the following sections, an overview of the research done in the various identified streams is provided. As shown in Table 1, the streams identified follow a specific flow: the first is based on the individual- and organizational-level perspective from the intrapreneurship literature; the next stream focuses on context orientation in research; further research examines the possible outcomes of intrapreneurship and in addition factors further promoting intrapreneurial activities. The research stream focusing on individual-level factors is divided into two sub-categories of 


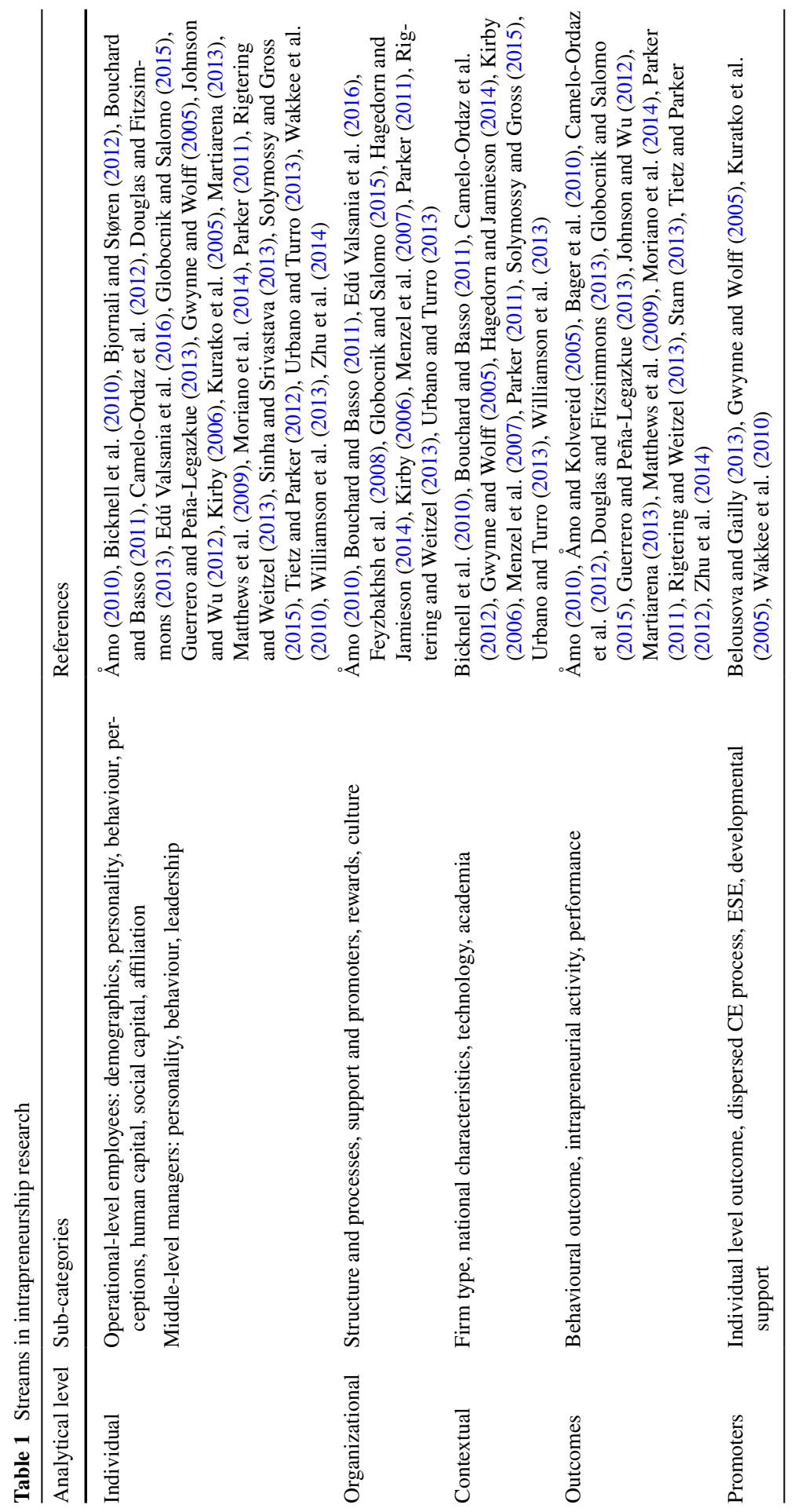


operational-level employees and middle-level managers, as they play different roles in the intrapreneurship process due to their relative positions in established organizations.

\subsubsection{Individual-level perspective on intrapreneurship}

Operational-level employees Various authors have examined factors predicting the innovative and entrepreneurial behaviour of the individual employee. An applied focus on demographic characteristics showed mixed results. Research work on education and age shows negative associations with innovation (Camelo-Ordaz et al. 2012). In contrast, other research shows that high levels of education increase the likelihood of intrapreneurship (Urbano and Turro 2013). Therefore, investigations focusing mainly on demographic variables are divergent and vague. In response, one approach often used in the entrepreneurship field to examine individual-level characteristics focuses on personality traits. Intrapreneurship researchers have tried to examine personality factors to identify intrapreneurs within organizations based on their specific traits (e.g. Williamson et al. 2013). Based on the Big Five model, researchers have described specific traits that point to innovative employee behaviour. Sinha and Srivastava (2013) examined the impact of personality traits and work values on innovative employee behaviour (the authors call it intrapreneurial orientation). Their research reveals that extraversion and the work values of altruism, creativity, management and achievement are positively associated with innovative behaviour. The results also show a negative association between neuroticism and intrapreneurial orientation. Research based on the entrepreneurial value system shows that values such as persistence, ambition, creativity, risk taking and optimism can be said to influence innovation performance (Camelo-Ordaz et al. 2012). When looking at these results, it should be borne in mind that the authors investigated individual-level factors in the context of creative firms and found that values such as creativity are of high importance by nature. As a further individual characteristic, initiative seems to play a key role, as employees with personal initiative are more likely to be intrapreneurs and are also more involved in intrapreneurial projects (Rigtering and Weitzel 2013). In line with this, Åmo (2010) identified employees as the initiators of and main contributors to innovation processes. The author argued that based on this, it is possible to determine if the innovation behaviour of employees is intrapreneurship (bottom-up) or rather CE (top-down) driven.

Zhu et al. (2014) also investigated personal characteristics and their research offers detailed insights. In the context of an intra-organizational idea contest, the authors examined the effect of the creativity and proactivity of employees on their performance in this contest. To this end, they measured the number of ideas contributed, the number of ideas accepted and the number of comments on others' ideas. The results show that a higher level of creativity is positively related to higher numbers of ideas being contributed, whereas a higher level of proactivity is positively related to higher numbers of ideas being accepted. Based on their research, the authors developed a framework of four different innovation roles: follower (low creativity and proactivity), proactive founder (low creativity and high proactivity), creative innovator (high creativity and low proactivity) and intrapreneur (high 
creativity and proactivity). Hence, they underlined the characteristics of intrapreneurs as follows: "they are a combination of thinker, doer, planner, and worker. They combine vision and action" (Zhu et al. 2014, p. 1440015-12).

One limitation of research focusing on personality is the static character of traits. To take into account a more dynamic perspective, research concentrating on entrepreneurial behaviour is also a research approach identified in this field. Drawing on the TPB, Kirby (2006) highlighted individuals' attitudes, perceived ability to be entrepreneurial and social support as relevant factors in fostering intrapreneurship. Research on different attitude types and entrepreneurial careers has shown that attitudes to income, independence and ownership are related to entrepreneurship, whereas intrapreneurship is related to a weak risk tolerance. Also, the motives for potential intrapreneurs to show a certain behaviour have been analysed. Research on financial, independence, recognition and role model motives undertaken by Tietz and Parker (2012) shows that the same motives that stimulate nascent venturing have the reverse effect on being selected by an organization into intrapreneurship. Closely linked to behaviour-and therefore the TPB - is the topic of perceptions. In intrapreneurship research, perceptions concerning risk and uncertainty in particular are of high relevance in distinguishing intrapreneurs from entrepreneurs. The results of research show that intrapreneurs are quite similar to entrepreneurs with regard to uncertainty and risk perceptions (Matthews et al. 2009). In contrast, intrapreneurs seem to be more elaborate planners, with higher growth expectations. The authors explained these results based on the established organizational environment of intrapreneurs, which forces them to engage in planning activities that in turn also lead to higher growth expectations. In addition, the research of Martiarena (2013) shows that intrapreneurs present greater levels of risk aversion and lower levels of expected earnings than entrepreneurs.

One main research stream focuses on the human capital of intrapreneurs. Following prior research, the sub-categories distinguish between general and specific human capital related to intrapreneurship. General human capital refers to skills, knowledge and experiences that are useful in multiple situations, whereas specific human capital refers to content-specific situations that are primarily useful in intrapreneurial situations. One main contribution referring to general human capital is the work of Parker (2011), who examined the issue of entrepreneurship or intrapreneurship. He identified several factors and pointed out that general human capital leads to start-up activities (entrepreneurship and intrapreneurship) — and to entrepreneurship in particular - as it is useful in various situations within and outside an existing organization. Other research applying human capital theory also points to the relevance of general human capital in terms of the provision of necessary entrepreneurial skills (Gwynne and Wolff 2005; Martiarena 2013) and competencies. Bjornali and Støren (2012) concentrated on different competencies and investigated their influence on innovative employee behaviour. They examined the effect of different types of competencies, as well as participation in entrepreneurship education programmes among European higher education graduate professionals. The authors' research shows interesting results, as professional/creative competencies and communicative/championing competencies increase the employees' probability of introducing innovations at work, whereas competencies related to efficiency and 
productivity do not. Bjornali and Støren (2012) highlighted the relevance of a third competence type, i.e. brokering. Employees with brokering competencies are able to combine knowledge with organizational knowledge, social capital and networking skills. Therefore, with regard to intrapreneurial behaviour, brokering competencies are of special interest. Entrepreneurship education programmes were also found to increase the likelihood of introducing innovations at work.

In contrast to the factors mentioned above, specific human capital focuses on specific - in this case intrapreneurship-oriented-skills and experiences. Similar to the case of entrepreneurship, opportunity recognition plays a significant role when it comes to intrapreneurship. Research results show that the ability to identify business opportunities enhances the opportunity for intrapreneurship (Urbano and Turro 2013). Detailed research stresses opportunity recognition as an important factor in defining intrapreneurs in contrast to entrepreneurs and employees: entrepreneurs recognize more business opportunities than intrapreneurs, but intrapreneurs recognize more business opportunities than employees (Martiarena 2013). Opportunity recognition and entrepreneurial opportunities have also gained in importance for engineers. Research based on a longitudinal study of graduate engineers revealed that engineers' tasks underwent a shift from recognizing engineering to entrepreneurial opportunities (Solymossy and Gross 2015). In addition, the authors investigated different types of knowledge and their value. The results estimate that potential knowledge (the adaptability to transfer knowledge) is of particular value to firms as it enables them to adapt to changes. Potential knowledge lies in the individual and can been seen as intellectual property. If firms do not value this, individuals will want to maximize their personal return on the potential knowledge and therefore will decide either to become entrepreneurs or to foster intrapreneurial activities. As a further factor, business planning activities are a distinctive feature of entrepreneurs versus intrapreneurs. Due to the established organizational environment, intrapreneurs are tied to planning activities and hence also show higher levels of business planning activities (Matthews et al. 2009). One relevant entrepreneurshipspecific aspect with regard to intrapreneurship again concerns the concept of ESE. Individuals' perceptions of their ability to meet competitive challenges will influences entrepreneurial employee behaviour. Johnson and Wu (2012) examined the influence of external entrepreneurial support and stated that ESE is a "pull" factor for entrepreneurship. In particular: "their perception of certainty may provide the extra confidence for an already overly optimistic individual, thereby boosting their entrepreneurial self-efficacy leading to the eventual exodus from the corporation" (Johnson and Wu 2012, p. 342). The crucial role of ESE is also part of the work of Douglas and Fitzsimmons (2013), who examined differences in entrepreneurial and intrapreneurial intentions. ESE was related to both entrepreneurial and intrapreneurial intentions, but showed a higher level of significance for entrepreneurial intentions. Douglas and Fitzsimmons speculated that individuals with higher ESE are more likely to engage in self-employed behaviour and individuals with lower ESE also intend to be entrepreneurial, but as intrapreneurs within an organization. In line with this, Guerrero and Peña-Legazkue (2013) examined specific human capital and its influence on corporate venturing activities. They investigated the effect of intrapreneurial experiences and found that employees with intrapreneurial experience are 
more likely to create a corporate venture for the organization. Their results also indicate that the effect of intrapreneurial experiences on corporate venturing is higher than that of other human capital forms based on education level. Similarly, Globocnik and Salomo (2015) stressed the relevant role of intrapreneurial self-efficacy. They argued that employees with high levels of intrapreneurial self-efficacy are convinced of their abilities and may even exhibit bootlegging behaviour to develop their ideas further.

As entrepreneurship and entrepreneurs are embedded in social systems, it is not surprising that another focus in intrapreneurship research is on social capital. Intrapreneurs' networks and their roles are issues in intrapreneurship research. The individual's personal network (Urbano and Turro 2013), networking skills (Gwynne and Wolff 2005) and relationships outside the organizations' boundaries (Bicknell et al. 2010) seem to be relevant individual characteristics of intrapreneurs. These results are especially in line with Pinchot's (1985) original idea of intrapreneurs and their ability to think across organizational boundaries. In line with social capital (Coleman 1988) and social network theory, the results indicate that social capital is a specific form of resource that originates from interaction and facilitates individuals' actions. A main requirement for benefiting from social ties and the capital residing in them is trust. As demonstrating intrapreneurial behaviour within an organization often means departing from the usual way of doing things and challenging confirmed habits, it is not surprising that trust also plays a key role in the intrapreneurial context (e.g. Edú Valsania et al. 2016). Wakkee et al. (2010) highlighted the relevance of trusting relationships between employees and managers in influencing employees' ESE perceptions and increasing their self-efficacy. These results are also in line with the work of Rigtering and Weitzel (2013), who indicated the importance of trust in managers as an influence on intrapreneurial behaviour.

A further research focus derives from the fact that intrapreneurs are embedded in established organizations and hence focuses on the individuals' organizational affiliation. Prior research has suggested that entrepreneurial employees leave the corporation and implement their own ideas due to dissatisfaction. However, in contrast to this assumption, Johnson and $\mathrm{Wu}$ (2012) revealed a different logic. Considering entrepreneurship versus intrapreneurship, they tested the job satisfaction model and the person-environment fit model. Their research does not support the assumption that employees quit the organization due to dissatisfaction; rather, their results show that nascent entrepreneurs leave the corporation with high levels of job satisfaction. The authors argue that this is the case because nascent entrepreneurs, whilst working as employees, collect experience of the industry and afterwards leave the corporation to start a new business within the same industry. Therefore, nascent entrepreneurs are satisfied with their job but still leave the corporation to start their own venture. Further research work taking into account affiliation to an organization shows that the individual's organizational tenure negatively affects intrapreneurship in terms of innovation performance. Camelo-Ordaz et al. (2012) argue that long organizational tenure is associated with a passive attitude to decision making, resistance to change and therefore a reduced willingness to exhibit innovative behaviour und implement new ideas. Another factor is the employees' organizational identification. Moriano et al. (2014) examined its effect on intrapreneurship and found 
organizational identification to be positively related to intrapreneurial behaviour. Employees identifying with their organization experience the organization's success and failure as personal success and failure, are strongly engaged and therefore show some "extra-role" behaviour. These employees are highly motivated to show behaviour over and above their organizational role und hence to engage in intrapreneurial behaviour.

Middle-level managers Besides the focus on the individual operational level employees, a second stream emerges from research concentrating on management issues and managers with regard to intrapreneurial behaviour within organizations. In this regard, middle-level managers' personalities and behaviour and their influence on employees are of particular interest. Research shows that managers' personalities and attitudes are key factors driving intrapreneurial activities within an organization (Bouchard and Basso 2011). As a further step, research has also examined managers' behaviour. Kuratko et al. (2005) noted the special role of middlelevel managers as they are a relevant tie between top-level management's CE perceptions and lower-level management's intrapreneurial initiatives. In their research, the authors focused on middle-level managers' entrepreneurial behaviour by examining their role with regard to intrapreneurship. Middle-level managers endorse, refine and shepherd entrepreneurial opportunities and as a further step identify, acquire and deploy necessary resources to pursue entrepreneurial opportunities. The authors emphasize that "middle-level managers endorse CE perspectives coming from toplevel executives and 'sell' their value creating potential to the primary implementers-first-level managers" (Kuratko et al. 2005, p. 705). They stress that there is an individual-level outcome of entrepreneurial behaviour. A personal positive evaluation affects the middle-level managers' perceptions and thus leads to engagement in entrepreneurial behaviour.

Not only has middle-level managers' individual entrepreneurial behaviour been investigated, but also middle-level managers' influence on other employees. Moriano et al. (2014) examined management practices and their effect on intrapreneurship. They examined the influence of leadership styles in combination with employees' organizational identification on intrapreneurial behaviour. Their research indicates that transformational leadership (associated with adopting the organization's vision and achievement of collective goals) is positively related to intrapreneurial behaviour. Furthermore, organizational identification mediates the relationship between transformational leadership and employees' intrapreneurial behaviour. This underpins the relevance of managers' behaviour and their potential to foster intrapreneurial behaviour. Also, authentic leadership, labelled as future-oriented, proactive and trustworthy leaders, is positively related to employees' intrapreneurial behaviour. Edú Valsania et al. (2016) investigated the relationship between authentic leadership and employees' intrapreneurial behaviour and possible mediators. Similar to Moriano et al. (2014), their results show that organizational identification partially mediates this relationship. Based on these research results, the authors note the relevance of an appropriate leadership style as an antecedent of intrapreneurship. 


\subsubsection{An organisational-level lens on intrapreneurship}

Based on the assumption that individual-level initiatives, as well as organizationallevel approaches such as CE, are necessary to enable intrapreneurial behaviour (Åmo and Kolvereid 2005), a second stream of research offers an organizationallevel lens on intrapreneurship. By focusing on organizational structures and processes that permit intrapreneurship, research offers insights into influential organizational characteristics such as the role of the business owner, planning activities or formalization (Bouchard and Basso 2011). Various formal management processes that allow strategic autonomy, for example, are relevant factors in ensuring an intrapreneurship-friendly environment (Feyzbakhsh et al. 2008; Globocnik and Salomo 2015). Furthermore, organizational-related promoters offer an appropriate physical environment that creates physical nearness and stimulates various aspects of cooperation, as well as a reduced hierarchy and bureaucracy to ensure knowledge sharing and joint idea generation (Menzel et al. 2007). Authors have also stressed organizational empowerment as one important factor. The concept of empowerment allows employees to develop proactive behaviour through the implementation of an organizational structure that aims for the autonomy and commitment of employees in decision-making processes. The experience of organizational empowerment is a success factor and even mediates the relationship between authentic leadership and intrapreneurial behaviour (Edú Valsania et al. 2016). Menzel et al. (2007) further highlight the need for new methods in the teaching and training of intrapreneurship. Simulations and action-orientated approaches are useful preparing employees for intrapreneurship. Therefore, management processes should also shed light on suitable training tools to pioneer the intrapreneurial behaviour of employees.

As a second sub-category, organizational support and promoters are said to play a crucial role in fostering intrapreneurship activities (Urbano and Turro 2013). In particular, the role of management in fostering intrapreneurship in practice is of considerable relevance, as management acts as enabler for demonstrating entrepreneurial behaviour within the organization. Parker (2011) argues that potential intrapreneurs do not express interest in entrepreneurship until management, for example, presents a suitable opportunity. Various studies have demonstrated that the realization of intrapreneurial activities requires management support (Feyzbakhsh et al. 2008; Kirby 2006). In particular, management's clear commitment to intrapreneurship is a precursor for intrapreneurial activities and as a further step an intrapreneurship-friendly environment within the established organization. In addition to management support, high availability of resources leads to higher levels of intrapreneurial behaviour (Menzel et al. 2007; Rigtering and Weitzel 2013). Therefore, access to resources is an important organization-related promoter of intrapreneurship. Not only do support by managers and the availability of resources affect potential intrapreneurs, but also the opportunity to participate in various decision-making processes influences intrapreneurship initiatives on the part of employees. Research states that low organizational participation (with employees being the main contributors to processes) and high horizontal participation (broadly defined jobs of employees) are positively related to intrapreneurship (Åmo 2010; Rigtering and Weitzel 2013). Closely linked is also the communication of organizational strategies 
to employees as a success factor, strengthening the commitment and participation of employees. To complement organizational support, rewarding intrapreneurs has also been examined in research. Besides honouring the innovative accomplishments of intrapreneurs (Globocnik and Salomo 2015), rewards provide a signalling effect within the organization und emphasize intrapreneurial behaviour as desirable (Kirby 2006; Menzel et al. 2007).

As well as the parameters presented above, an underlying success factor of intrapreneurship is an organization-wide intrapreneurship culture. Authors have shown that the development of an intrapreneurial mindset allows organizations to foster an intrapreneurship culture and further facilitates organizational change (Hagedorn and Jamieson 2014). As intrapreneurs are characterized by their broad mindset, enabling them to cooperate and generate ideas across organizational boundaries, the culture needed is defined by trial and error, an innovative mindset and opportunities for experimenting and continuous refinement (Hagedorn and Jamieson 2014; Kirby 2006; Menzel et al. 2007).

\subsubsection{Context orientation in intrapreneurship research}

Besides the perspectives concerning the influence of individual- and organizationalrelated factors on intrapreneurship, research in the field also focuses on context orientation. Researchers have examined not only different firm types, but also the national level, as well as the technological and academic context.

The first stream consists of research work concentrating on different firm types. Bouchard and Basso (2011) examined factors at the organizational level of small and medium sized enterprises (SMEs). The authors aimed to link the organizational concept of EO with the individual-level concept of intrapreneurship. By examining the effect of managers' personalities and organizational characteristics on EO and managers' attitudes on intrapreneurship, Bouchard and Basso identified two different types of SMEs: traditional SMEs (with a central role of the owner, limited planning activities and informal structure) and in contrast to this, "miniature large firms" (with less centrality of the owner, more planning and some formalization of structure). From this perspective, EO and intrapreneurship are not simple correlated constructs, as it is possible that firms will show various combinations of EO (high or low) and intrapreneurship (high or low). Hence the authors propose that in traditional SMEs high EO will be associated with low or no intrapreneurship, whereas in miniature large firms high EO will be associated with diffuse intrapreneurship activities. Camelo-Ordaz et al. (2012) took a closer look at micro firms in the creative business sector. The authors investigated individual characteristics and intrapreneurs' entrepreneurial value systems (e.g. creativity) with regard to innovation. Due to the creative context, the authors pointed especially to the role of business background. Business background, namely possessing the necessary managerial skills, was found to have a negative influence on innovation performance in micro firms, whereas creative background was found to exert a positive influence on innovation performance. Looking at these results, the special context of creative firms should be borne in mind. Furthermore, the field of business seems to be an interesting factor regarding intrapreneurship. Parker's (2011) research shows 
that business-to-customer opportunities are associated with entrepreneurship and business-to-business opportunities rather lead to intrapreneurship, possibly due to industry-specific knowledge, greater access to resources and the higher legitimacy of established organizations.

Besides the perspective on various firm types, one paper also considered the national-level perspective. As well as individual-level factors, Urbano and Turro (2013) examined external factors (at the national level), such as fear of failure, successful storytelling and procedures for creating a company. The authors argue that a high level of education, the individual's personal network and the ability to identify business opportunities increase the opportunity for intrapreneurship. However, surprisingly research displays no significant effect of external factors, which are probably diminished by the need to achieve economic results.

In addition to the diverse perspectives mentioned above, two other streams in intrapreneurship research have emerged as an answer to changed conditions in practice. One such stream concentrates on intrapreneurship in the technological context. As intrapreneurship is closely linked to innovation, this is not surprising. One theme is the new role of engineers within organizations. Due to changes in the work environment, engineers are facing managerial responsibilities within firms and contribute to innovations throughout the whole innovation process. Therefore, the role of engineers has changed. Menzel et al. (2007) concentrate on technology intrapreneurs and describe how engineers become active in intrapreneurship. They identify organizational-related promoters of engineers' intrapreneurship. The physical environment, reduction in hierarchy and bureaucracy, rewarding behaviour, coaching for intrapreneurs and available resources are shown to be relevant factors. In addition, Williamson et al. (2013) focus on the new role of engineers. In contrast to Menzel et al. (2007), who focused on organizational-related factors, they examine various personality traits (For detailed results on all tested traits see Williamson et al. 2013, p. 161.). The results reveal that engineers differ from non-engineers and the authors indicate the relevance of this result with regard to finding engineers fitting into the new role within firms. Research based on a longitudinal study of graduate engineers also reveals that engineers' tasks have undergone a shift from recognizing engineering to recognizing entrepreneurial opportunities (Solymossy and Gross 2015). Based on the new role of engineers, the development of skills has also become the focus of research. Gwynne and Wolff (2005) provided some insights into a special programme for (women) scientists entailing networking, workshops, advice and mentoring to develop intrapreneurial skills.

A further research stream focuses on intrapreneurship in the context of academia. Kirby (2006) called for the creation of entrepreneurial universities to allow students and staff to commercialize their intellectual property and ideas. He argued that universities have spent decades on learning how to routinize and control processes and therefore are facing barriers in developing an entrepreneurial mindset. Hence, by drawing on individuals' attitudes, perceived ability to be entrepreneurial and social support (TPB), as well as intrapreneurship theory, he highlighted relevant factors for developing entrepreneurial universities. With regard to intrapreneurship, he especially noted the need for management support of entrepreneurship, a university-wide model of entrepreneurship, an intrapreneurial culture and the rewarding 
of intrapreneurs. Bicknell et al. (2010) also address the topic of intrapreneurship in academia and focus on academic staff engaging in knowledge transfer activities. The underlying motivation of these academics is to use their academic knowledge for a wider purpose than research and teaching. The authors term the knowledge transfer among active academics as academic intrapreneurship. In their research, they identify "pull factors" for engaging in knowledge transfer. For instance, academic intrapreneurs are proactive in networks and relationships outside academia and value the moderate risk of being entrepreneurial within the university. In particular, proactiveness and risk aversion point to academics having an intrapreneurial role.

Hagedorn and Jamieson (2014) also focused on intrapreneurship in the academic context and highlighted the need for an entrepreneurial mindset, but instead of concentrating on staff in particular, they focused on how organizational change in academia can be implemented. The authors argued that academia is facing several challenges (e.g. tightening budgets and intensive competition) and therefore an intrapreneurial mindset is necessary to redefine academia's strategic capabilities. Furthermore, this requires the collective development of mental modes that encourage an intrapreneurial and innovative mindset in academia.

\subsubsection{Outcome lens on intrapreneurship}

The fourth research stream that emerged applied an outcome perspective on intrapreneurship. Various studies have focused on possible outcomes of intrapreneurial behaviour. As intrapreneurship is a sub-field of entrepreneurship, one sub-category concentrates on the difference between entrepreneurship and intrapreneurship. By focusing on possible behavioural outcomes of intrapreneurship, authors have examined the issues of the differences between entrepreneurship and intrapreneurship. As already explained in 4.2.1, based on research multiple distinguishing features have been investigated: expectations, uncertainty, risk preference, human capital, job satisfaction, field of business and intentions (Douglas and Fitzsimmons 2013; Johnson and Wu 2012; Matthews et al. 2009; Parker 2011). Even motives have been considered to differentiate possible nascent venturing from possible nascent intrapreneurship (Tietz and Parker 2012). However, Parker (2011) also stated that there are unobservable attributes that result in entrepreneurship rather than in intrapreneurship. With regard to $\mathrm{CV}$, research points to intrapreneurial experience as a specific form of human capital that leads to a higher willingness to engage in CV activities (Guerrero and Peña-Legazkue 2013). Only one study in the sample investigated the outcome perspective at the national level. Based on the idea that knowledge created in an organization is an important source of entrepreneurial opportunities, Stam (2013) examined innovation indicators in correlation with total entrepreneurial activity (TEA) and entrepreneurial employee activity (EEA) at a national level. The results show that innovation indicators such as gross expenditure on R\&D are positively related to EEA but are not related or are even negatively related to TEA. Stam (2013) argued that knowledge and innovation are primarily linked to intrapreneurship. Radical innovations are likely to be recognized by employees within knowledge-intensive organizations. Therefore Stam (2013) clearly linked innovation to intrapreneurship and stated that entrepreneurship is only marginally innovative. 
A further sub-category deals with intrapreneurial activities in detail. Åmo and Kolvereid (2005) examined factors predicting innovative behaviour. They tested different models and the proportion of variance in innovation behaviour: one model based on the CE literature (an organization's strategic orientation towards entrepreneurship), one model based on the intrapreneurship literature (intrapreneurial personality) and a combined model. The results showed that the combined model of CE and intrapreneurship explained a significantly higher proportion of variance in innovation behaviour. This underlines Amo and Kolvereid's (2005) point that innovative behaviour is a result of both CE and intrapreneurship. In further research, Åmo (2010) again pointed to the need for clarification of the similar but diverging terms of CE and intrapreneurship. In his research, he clearly defined employees' innovation behaviour as a connection between the two theoretical perspectives, bottom up and top down.

Similar to the work of Amo and Kolvereid (2005), Rigtering and Weitzel (2013) developed a two-step model of intrapreneurship based on prior work. Their work shows that employees need to address two steps to be intrapreneurs. First, intrapreneurship is stimulated by the organization, as employees are able to develop and identify opportunities (intrapreneurial behaviour). As a second step, the employees are actively involved in innovation projects (intrapreneurship). Examining formal and informal work contexts, the authors state that horizontal aspects of participation at work, available resources and trust in managers lead to higher levels of intrapreneurial behaviour (concerning innovative behaviour and personal initiative, but not risk taking). In a second step, their research shows that employees exhibiting innovative behaviour and personal initiative are more likely to be intrapreneurs and are also involved in more intrapreneurial projects. Risk taking does not have a significant effect. Thus, the authors show that intrapreneurship is only indirectly affected by work context, namely through individual-level factors, such as innovative workplace behaviour and personal initiative. To further stimulate intrapreneurship, management and leadership styles play an important role and help foster the existing intrapreneurial potential of employees (Moriano et al. 2014). The intrapreneurial behaviour approach combines the individual- and organizational-level perspectives, as well as the intrapreneurship and CE levels, and is therefore in line with Åmo's (2010) notion that the perspective on employees' innovative behaviour takes into account management's role as an enabler and employees' individual decisions to engage in innovative behaviour.

Research on employees' innovation behaviour provides diverse approaches in further describing intrapreneurs. Based on an ownership dimension, the research of Martiarena (2013) divided intrapreneurs into four different categories to differentiate between entrepreneurs, engaged intrapreneurs (new business activity for corporations, expecting to demand an ownership stake), intrapreneurs and employees (both within a corporation). The results show that the self-perception of entrepreneurial skills is positively related to entrepreneurship and engaged intrapreneurship, as intrapreneurs who believe in their own entrepreneurial ability demand an ownership stake of a new corporate business and become engaged intrapreneurs. Nonetheless, Martiarena (2013) indicates that engaged intrapreneurs are similar to entrepreneurs, whereas intrapreneurs are similar to employees. Bager et al. (2010) further divided 
intrapreneurs into four sub-categories: project intrapreneurs, venture intrapreneurs, spin-off entrepreneurs and independent entrepreneurs. Their results reveal that intrapreneurs are similar to entrepreneurs, but appear to be more experienced and growth oriented. Likewise, spin-off entrepreneurs seem to be more experienced and growth oriented than independent entrepreneurs. Moreover, they quickly attain higher performance than their independent counterparts. In addition, the authors estimate that these four sub-categories need further examination and that management support appears to play a key role.

One sample article also examined a specific form of employee behaviour of intrapreneurs: bootlegging. In this case, employees develop their ideas without formal legitimization by ignoring formal structures. Globocnik and Salomo (2015) examined whether formal management processes and intrapreneurial self-efficacy lead to bootlegging behaviour. The authors show that strategic autonomy, rewards for innovation accomplishments and also intrapreneurial self-efficacy are indicators for bootlegging behaviour (bootlegged projects, bypassing official channels and providing own resources to develop ideas). Surprisingly, the results show a negative effect of front-end formality (formal mechanisms for idea exploration, development and selection) on bootlegging. This implies that to some extent formal structures are needed to guide employees' innovation behaviour.

Only a few papers have applied an outcome perspective, investigating the relationship between intrapreneurship and measureable performance: intrapreneurial behaviour and its influence on performance in an idea contest (Zhu et al. 2014), business performance of spin-off entrepreneurs (Bager et al. 2010) and innovation performance in creative firms (Camelo-Ordaz et al. 2012). Hence the sample articles have mainly focused on performance in terms of innovative or creative outcomes, rather than objective business performance measures, such as key financial data.

\subsubsection{Factors promoting intrapreneurship}

The papers in the last research stream deal with additional factors promoting intrapreneurship. Kuratko et al. (2005) highlight the key role of middle-level managers in their research. Due to their role and tasks in motivating employees, acquiring necessary resources and selling innovative ideas to top-level management, middle-level managers can themselves be defined as intrapreneurs. The authors therefore also argue that middle-level managers behave in an entrepreneurial manner and that there is an individual-level outcome of this behaviour. As a further step, positive evaluation of this behaviour affects individual perceptions and leads to increased engagement in intrapreneurship in the future. Therefore, the role of managers is crucial in motivating operational-level employees, but at the same time the entrepreneurial behaviour undertaken also promotes the intrapreneurial initiatives of employees and managers.

Belousova and Gailly (2013) also point to the promotional role of middle-level managers and present interesting results concerning the contribution of different organizational members in line with the CE process. The so-called dispersed $C E$ process is divided into the stages of discovery, evaluation, legitimation and exploitation. The authors show that different levels of organizational managerial membership 
(top-, middle- and operating-level) are involved in this process. The role of middlelevel managers is crucial as they encourage operational-level employees to work on innovative ideas and at the same time champion ideas in relation to management. In addition, the various stages of the process (e.g. evaluation, legitimation) are promoters, facilitating feedback, evaluation, continuous adjustment and experimentation.

In line with this, Wakkee et al. (2010) argue that with regard to intrapreneurial behaviour, there is a reciprocal connection between cognition, environment and behaviour. Thus intrapreneurial behaviour is not just the result of ESE. As showing behaviour allows feedback, intrapreneurial behaviour is also a determinant of ESE. The authors state that ESE has a positive effect on entrepreneurial employee behaviour, as a person's perception of being capable of behaving entrepreneurially is reflected in actual entrepreneurial behaviour. A further promoting factor that has emerged from research is developmental support in the form of coaching (Menzel et al. 2007; Wakkee et al. 2010). As employee coaching by managers provides access to resources and strengthens the awareness of intrapreneurship, the role of coaching in entrepreneurial employee behaviour and ESE has been investigated. The results reveal a positive effect of coaching on intrapreneurial behaviour, demonstrating that coaching can be an important factor promoting intrapreneurship. In addition, workshops, developmental advice and mentoring (Gwynne and Wolff 2005) provide developmental support in fostering intrapreneurial skills and promoting intrapreneurship.

\section{Discussion and paths for future research}

The purpose of this paper was to examine intrapreneurship research and identify the current research focus in the field. By mapping the current research, the paper has clearly distinguished intrapreneurship as distinct from the organizational concepts of corporate entrepreneurship and entrepreneurial orientation. The results of the systematic literature review indicate different analytical clusters of research focusing on intrapreneurship: studies related to individual- and organizational-level factors, contextual-oriented research, an outcome lens on intrapreneurship and research concentrating on possible promotional factors.

The articles explored in this review offer an overview of interesting and current key aspects in intrapreneurship research. Based on the results, it can be argued that corporate entrepreneurship as a top-down approach and intrapreneurship as a bottom-up approach (Åmo and Kolvereid 2005; Rigtering and Weitzel 2013; Sinha and Srivastava 2013) are definitely linked to each other. As stated, "there will not be any innovation without the individual being involved" and it "also involves the organisation as a given process parameter" (Menzel et al. 2007, p. 734). This is also in line with earlier conceptual work (e.g. Bouchard and Basso 2011), which pointed to the need for a combined perspective on the intrapreneurship phenomenon and the necessary integration of individual and organizational concepts. As researchers (e.g. Kuratko et al. 2005) have indicated, middle-level managers support $\mathrm{CE}$ activities from top-level managers and also promote their value to operationallevel management; middle-level managers' role is to link the constructs of CE and 
intrapreneurship within firms. Furthermore, due to their specific role in selling ideas and acquiring resources, middle managers themselves are intrapreneurs.

A further interesting finding is the key role of entrepreneurial self-efficacy in fostering intrapreneurship. Research points to the possibility that the individual's perceived ability influences intrapreneurial behaviour. In particular, prior research has investigated individuals' choice of entrepreneurship and employment but has "failed to recognise the intermediate case where the individual, as an intrapreneur, can behave entrepreneurially as an employee within a corporate context" (Douglas and Fitzsimmons 2013, p. 116). In particular, this corporate context enables the individual to gain entrepreneurial experience as an intrapreneur in a safe setting within an organization and hence increases entrepreneurial self-efficacy. In a further step, this increase in ESE can result either in creating an independent firm (entrepreneurship) or an ownership stake in a new corporate business as an engaged intrapreneur. However, ESE seems to be a key factor in promoting the intrapreneurial behaviour of employees and seems to have a leverage effect on intrapreneurship.

Besides the research emphasis on individual factors, organizational aspects, outcomes and promoting factors, the sample articles were applied in diverse contexts. Notably, studies investigated not only the business context, but also technological and academic contexts. In particular, the applied focus on intrapreneurship in academia characterizes intrapreneurship as a broad concept and points to employees' intrapreneurial activities in public sector institutions. With regard to the changed role of academia and the third mission of universities (Zomer and Benneworth 2011), the intrapreneurship research illustrates recommendations concerning the design of knowledge transfer processes and the establishment of an intrapreneurship culture in academia.

In addition to the various research streams identified, the lack of a consistent definition of intrapreneurship is recognized. The terms used in the articles examined vary according to their particular research focus. Synonyms such as "employee entrepreneurship" emerge and authors focusing on intrapreneurship at the individual level use the term "corporate entrepreneurship" (e.g. Urbano and Turro 2013). Therefore, clarifying the intrapreneurship concept seems to be challenging. The definition of intrapreneurs seems to relatively clear, as all authors except one offer similar definitions of entrepreneurial employees within established organizations. Only Camelo-Ordaz et al. (2012) define intrapreneurs as founders within organizations.

\subsection{Future research agenda}

The results of the systematic literature review indicate that intrapreneurship research is an emerging field. Prior research has hardly focused on the individual intrapreneur's perspective. To close this research gap, the paper used a narrow focus concentrating on intrapreneurship at the individual level. Hence the related concepts of corporate entrepreneurship and entrepreneurial orientation were excluded from the investigation and the paper did not present a holistic picture of the concepts as shown in Fig. 1. Furthermore, only publications in journals clustered in the relevant subject areas of AJG and VHB were included to illustrate the state-of-the-art in this 
specific field. Based on this narrow focus, the review yielded a comparatively small number of articles. However, the review results close a well-defined research gap and offer fruitful insights which will be of help in developing the intrapreneurship field. The SLR adds value by distinguishing the different analytical levels applied in intrapreneurship research, synthesizing prior research in the field and providing an overview of relevant research issues, as well as starting points for future research. Figure 3 summarizes the research streams identified (in light grey) and integrates them with possible future research agendas based on the results of the SLR.

Research focusing on the analytical level of individual factors, such as personality and behaviour, delivers insights into operational-level employees. Based on the specific characteristics of intrapreneurs, such as being innovative and building relationships even outside the organization, research especially highlights the relevance of human and social capital. Research takes into account specific human capital, such as ESE and the possibility to collect intrapreneurial experience and its influence on intrapreneurial behaviour. In particular, when employees have the chance to collect intrapreneurial experience by trial and error within an established organization, entrepreneurial skills and competencies can be fostered. This in turn leads to higher self-perceptions of the personal ability to show intrapreneurial behaviour. By concentrating on organizational-level factors, authors mainly underline the supporting function of organizations and management's key role in developing an intrapreneurship-friendly structure and culture. Beside aspects grounded in an organization's structure, such as autonomy and organizational empowerment, management's role in particular is of high relevance. The commitment of management, access to resources and appropriate rewarding of intrapreneurs are organizational-related enablers of intrapreneurial initiatives. In addition to structure and processes that promote intrapreneurship, an organization-wide intrapreneurial mindset is also important. Employees experiencing a culture of trial and error are more willing to show some "extra-role" behaviour, experiment and generate new ideas.

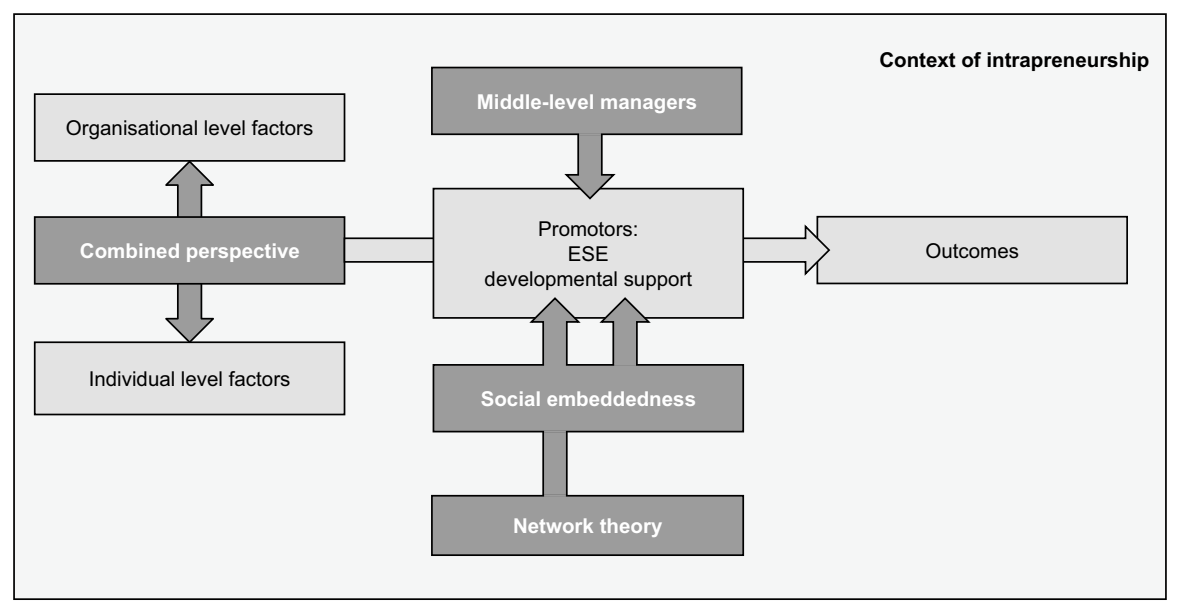

Fig. 3 Research streams identified and future research directions based on the SLR results 
An outcome orientation in intrapreneurship research focuses on behavioural outcomes (entrepreneurship vs intrapreneurship) rather than measureable intrapreneurship performance. Hence individual differences between entrepreneurs and intrapreneurs have been investigated. In addition, intrapreneurial behaviour is a well-researched topic. Based on individual factors such as proactiveness, creativity and an ownership dimension, prior research has developed categories to differentiate intrapreneurs from entrepreneurs and others. In this regard, researchers have shown that there are further sub-categories for differentiating diverse intrapreneur types, e.g. intrapreneurs from engaged intrapreneurs. Beside behavioural outcomes, work on measureable intrapreneurship effects on an organization's performance is also necessary. Prior research focusing on intrapreneurship and its outcomes has been based on the organizational level, examining the influence on organizations' performance (e.g. in idea contests). Based on this, Bierwerth et al. (2015) performed a meta-analysis to investigate the CE-performance relationship. Although their research model is based on different CE activities, the authors provide first hints concerning how strategic renewal and innovations affect different types of performance. Thus, future research should concentrate on the intrapreneurship-performance relationship, investigating individual intrapreneurs' capabilities (serving as specific human capital) and their contribution to organizations' performance.

The model also considers promoters, either individual- or organizational-driven, as intensifiers of individual and organizational factors leading to various outcomes. Based on the content analysis of the sample articles, it can be stated that in particular ESE and the availability of developmental support (both presented in the model in Fig. 3) are catalysts or (if absent) constraints for employees' intrapreneurial initiatives. It can be assumed that promoting factors such as intrapreneurial experience and ESE can serve as intensifiers of intrapreneurial behaviour. Employees who behave entrepreneurially within the safe setting of an established organization can develop and foster entrepreneurial skills, show intrapreneurial behaviour and experiment on new ideas. If all this is accompanied by an intrapreneurship-friendly culture and guidance of managers, continuous refinement of ideas and a learning cycle for intrapreneurs is possible. These learning effects especially serve as helix by increasing the individual's perceived ability and ESE and hence the likelihood of intrapreneurial activities.

Also, a too narrow context orientation of intrapreneurship research and therefore an emphasis exclusively on the business context are outdated. The changing career requirements of engineers and major challenges in academia show that the intrapreneurship approach has found its way into various contexts. While the paper provides interesting findings concerning intrapreneurship, further emerging research themes can be highlighted. Hence in Fig. 3, as well as the research streams identified, related future research issues are also presented (in dark grey and bold text). Therefore, the model also includes new research ideas.

First, to deepen understanding of entrepreneurship within firms, a combined perspective, focusing on corporate entrepreneurship in combination with intrapreneurship, is needed and would give interesting insights into how these two concepts enhance entrepreneurial employee behaviour within firms. A combined approach allows linking of the individual and organizational levels and applies a "factor mix". As already postulated in prior research, an integrative research approach and therefore a combined model (e.g. Åmo and Kolvereid 2005) promises the identification of meaningful 
factors to predict intrapreneurial behaviour in firms. However, research applying integrative models and considering organizational- as well as individual-level factors is rare. Therefore, there is a call for far more research linking the two levels and concentrating on connecting the top-down CE and bottom-up intrapreneurship approaches. Furthermore, in this context, researchers should consider the crucial role of the organization's management in the interplay between organizational and individual initiatives towards intrapreneurship. Most of the research applying the organizational-level lens investigates the supporting role of the organization and management, but does not pay attention to the stimulating role of management. Hence, there is a need to explore the double role of management as enablers of intrapreneurship on the one hand and impulse generators for intrapreneurial behaviour on the other.

With reference to this, research has recognized the influencing role of middlelevel managers as bridging actors (Kuratko et al. 2005). As a result of middle-level managers' closeness to employees but also top management, they play a key role in facilitating and fostering intrapreneurship in organizations. Based on the organizational commitment and orientation to intrapreneurship, middle-level managers have a double role, acting as enablers and a stimulus for intrapreneurial activities. As research has underlined, managers' coaching of employees provides a breeding ground for intrapreneurship. The coaching provides access to resources, raises the awareness of intrapreneurial behaviour and in particular cases even has a positive influence on the self-efficacy of employees. The review results reveal a positive effect of coaching on intrapreneurial behaviour, but not on individual entrepreneurial self-efficacy. One reason stated in the research is that perhaps only trusting coaching relationships lead to an increase in ESE. Edú Valsania et al. (2016) also highlight trust as an antecedent of intrapreneurial behaviour and in particular trusting relationships with employees' supervisors as enablers of intrapreneurial employee behaviour. Therefore, it can be argued that middle-level managers contribute in particular to promoting factors such as the ESE of employees, but only if trusting relationships between middle-level managers and employees exist. Hence the leadership style of managers is also an important antecedent of intrapreneurial activities in organizations. Leadership styles, characterized by a future orientation, participation of employees and proactive and authentic leaders, influence employees' intrapreneurial behaviour (e.g. Moriano et al. 2014) and are an important foundation for trusting ties between managers and employees. In addition, due to managers' own role of motivating employees, acquiring resources and challenging innovative ideas with the top-level management, middle-level managers themselves can be defined as intrapreneurs. Thus, besides enabling the intrapreneurial initiatives of operationallevel employees, middle-level managers themselves serve as a stimulus for intrapreneurship. Within the organization, they offer valuable impulses for intrapreneurship and serve as role models for potential intrapreneurs. Research in this area should be strengthened to discover relevant intrapreneurial skills and competencies of managers, necessary to support employees and their innovative ideas on the one hand and to initiate intrapreneurial behaviour within the organization on the other hand.

By coaching employees, managers provide an important resource for potential intrapreneurs: developmental support. As intrapreneurship research shows, developmental support in the form of coaching, mentoring and advice is an important promoting factor 
of intrapreneurship. Employees value this as it supports them in gaining knowledge and entrepreneurial skills. The tasks and competencies of intrapreneurs comprise perhaps an even more essential future research direction. When looking at the typical tasks and challenges intrapreneurs face when developing ideas, the results of the review underline the importance of so-called brokering competencies. As Pinchot (1985) stated, the ability to think across different organizational units boundaries is crucial. To push innovation and strategic renewal, the exchange of ideas and knowledge is important. Intrapreneurs are proactive in networks and establish relationships inside and outside the organization. These ties enable them to be open-minded, discover business opportunities and develop brokering competencies. Therefore the social embeddedness of intrapreneurs should be taken into account when investigating the development of intrapreneurial behaviour on the part of employees. One of the main differentiating characteristics of intrapreneurs versus entrepreneurs is the embeddedness in an existing organizational structure (Camelo-Ordaz et al. 2012; Pinchot and Pellman 1999) and thus it is surprising that such embeddedness is underrepresented in the intrapreneurship field. The surrounding social context of intrapreneurs within the organization and the relationships between employees and ties to different organizational departments should be on the research agenda, as these factors influence the development of specific human capital and intrapreneurial behaviour. The organizational settings of intrapreneurial activities within organizations define an intrapreneur as a team player. Therefore, future research should integrate the individual- and team-level perspectives. Only few researchers have focused on team-level intrapreneurship. However, against the background of intrapreneurs as informal leaders who push innovative ideas further, this topic is emerging.

Not only within the established organization, but also outside it, intrapreneurs are part of a social system. To broaden the understanding of intrapreneurs' social embeddedness, research should also focus on the whole network of intrapreneurial employees. As mentioned above, trust and relationships are of high relevance for intrapreneurs and promote intrapreneurial behaviour. Both factors are typical sub-themes of another research field in entrepreneurship_social network theory (added as new field in Fig. 3). In this context, an individual's network is defined by relationships and trusting ties (e.g. Granovetter 1973) from all social spheres, including the work and non-work context (Dobrow et al. 2012). Network theory shows that ties to different people, as well as the social capital (Coleman 1988) residing in these relationships, influence people's development (e.g. Higgins and Kram 2001) and attitudes and behaviour. Urbano and Turro (2013) examined network factors in the intrapreneurship context and showed that an individual's personal network influences the likelihood of intrapreneurship. Hence it can be argued that employees' network ties influence team-level and individual-level intrapreneurship. This leads to the fourth recommendation for future research, namely combining intrapreneurship and network theory and paying attention to the overlap between these two concepts. Research in this area promises useful insights into whether or not networks and trusting relationships influence the ESE of employees and as a second step intrapreneurial intention. Furthermore, this provides the possibility of investigating intrapreneurs' networks and gaining answers to the question of whether such relationships facilitate the development of intrapreneurial behaviour. Also, more research on the role of social capital — inside and outside the established organization — is needed as 
intrapreneurs develop and operate in an already established social setting and not apart from it. Research focusing on this would offer detailed insights into an individual's network and its relevance for developing specific human capital and social capital. Prior research assumes that trusting ties facilitate the development of intrapreneurial skills and allow access to other intrapreneurs who act as role models and in addition enhance the development of ideas across organizational departments.

Another interesting field of future research derives from the stream of intrapreneurship in the academic context. Academia also has to meet the demand to be innovative and generate competitive advantage, just as firms do. As universities are facing new and various challenges, they are forced to be entrepreneurial and become so-called entrepreneurial universities. As noted in research, universities should generate a university-wide model of entrepreneurship culture to foster the innovative behaviour of students and staff (Kirby 2006). This highlights the new role of academic staff: academics should develop an intrapreneurial mindset to think across university departments' boundaries and redefine the university's capabilities. In addition, the academic staff operating in teaching, impart entrepreneurial competencies to their students. This strengthens the modification from traditional to entrepreneurial universities and creates an intrapreneurship culture. In addition, the relevance of successful knowledge transfer gains in importance. To realize the transfer of knowledge from research and to recognize business opportunities, there is a need for intrapreneurial approaches and research staff at universities need to develop entrepreneurial skills (Bicknell et al. 2010). In contrast to universities' traditional goals of routines and control processes, nowadays they have to encourage a culture associated with trial and error and experimentation (Hagedorn and Jamieson 2014). Research in this field is very rare and is mainly based on innovation research. The field of entrepreneurship has almost entirely neglected the topic of intrapreneurship in academia until now. Hence future research should investigate the intrapreneurship culture of universities and the tasks and competencies needed for successful knowledge transfer, as well as the knowledge transfer process itself.

All the future research agendas mentioned above place an emphasis on one particular analytical level. This clear focus on a single level offers deeper insights into intrapreneurship topics. Nevertheless, this clearly focused research has a certain limitation. The results will offer detailed insights at the expense of a holistic view of the intrapreneurship phenomenon. A holistic view, integrating various analytical levels, including individual, organizational, team, network, contextual, environmental and other factors, is the only approach that will allow a comprehensive picture of intrapreneurship. Therefore, there is a call for holistic research using a processual perspective on intrapreneurship. This would guarantee the adoption of an integrative lens closing the gap between examination of the antecedents of intrapreneurship, innovative employee behaviour, influencing factors and intrapreneurship activities. In addition, such a research approach would also answer the call for research that combines the various theoretical foundations of the intrapreneurship field. Research in this area is complex, so one main task would be to combine CE, EO, intrapreneurship and other concepts from entrepreneurship and management theory. Although a considerable challenge, this research approach would have high impact in the research field, as it would add to the clarification of the intrapreneurship field and would highlight intrapreneurship as a holistic approach that exists at the intersection of various thematic fields. 
Based on the holistic model in Fig. 3, the research streams and future research agenda presented additionally provide further clarification of the intrapreneurship concept. Although definitions depend on the research focus and goals, this paper makes a contribution by defining intrapreneurship at a general level: intrapreneurship is entrepreneurial behaviour on the part of employees within established organizations in various contexts (private and public sector) that is proactively initiated by employees. Based on specific human capital, as well as social capital, so-called intrapreneurs perceive that they have the ability to engage in intrapreneurial behaviour and thus proactively apply their entrepreneurial know-how to push new ideas in the safe setting of an already existing firm. The engagement in entrepreneurial tasks across their unit boundaries leads to the on-going development of entrepreneurial skills and enhanced ability to show "extra-role-behaviour" and finally results in organizational outcomes, such as strategic renewal and innovations. Intrapreneurs-employees but also entrepreneurial masterminds - value autonomy, trustworthy leaders and participation in decision making and strongly identify with their organization. Although intrapreneurship is a bottom-up approach, the two aspects are required for intrapreneurs' potential to unfold: proactive intrapreneurs but also organizational support and an appropriate culture that allows experimentation, feedback and learning by trial and error.

\section{Conclusion}

Intrapreneurship is an emerging field in research and is also gaining increasing attention in organizational practice. A deep understanding of factors influencing the intrapreneurial behaviour of employees is important for researchers, but also for firms aiming to foster intrapreneurship. This paper provides a systematic literature review on individual-level intrapreneurship and hence offers an orientation for researchers to identify relevant research issues. Prior research has also focused on intrapreneurship, but has only investigated single aspects and therefore no comprehensive picture of the intrapreneurship field has yet been provided. In particular, the narrow focus on individual-level intrapreneurship in contrast to $\mathrm{CE}$ and $\mathrm{EO}$, as well as the interplay of the concepts, serve as the basis for a clarification of the intrapreneurship concept and much clearer justification of future research.

Based on the systematic literature review, this paper presents the state of research on intrapreneurship. Five clusters are built, dealing with the various analytical levels applied: organizational and individual, context orientation, outcome level and possible promoters. The paper provides insights into these research areas and integrates them within a model that shows existing research streams and possible paths for future research initiatives. By clustering the research based on the perspective applied, the paper is the first to give an overview of analytical levels and show possible linkages between the various lenses on intrapreneurial behaviour. Hence the paper contributes to the research field as a first step towards a holistic research model of intrapreneurship. Besides presenting the state of research and future research agendas, the paper also reveals the impetus for enabling and fostering intrapreneurship in practice. The research results allow insights concerning factors influencing the intrapreneurial behaviour of employees and are of high relevance for practice. 


\subsection{Implications for practice}

The review has highlighted several future research themes, in addition to the suggestions made by the articles reviewed. In addition, the research contributes to the field of intrapreneurship in practice by underlining relevant issues. The findings suggest that entrepreneurial orientation and the implementation of corporate entrepreneurship are not enough to increase intrapreneurial behaviour. Rather, organizations should provide a suitable environment that enables intrapreneurship and initializes intrapreneurial activities on the part of employees. Hence organizational factors such as strategic autonomy, coaching of potential intrapreneurs and available resources are crucial, but the development of an intrapreneurial culture and management's clear commitment to intrapreneurship are also needed. To foster intrapreneurship, both aspects are crucial, as top management's vision of innovativeness and employees' entrepreneurial initiatives are both necessary to realize intrapreneurship.

Middle-level managers are key in combining the perceptions of top management and the intrapreneurial activities of employees. Organizations should be aware of the "bridging role" of these managers and give them an active part in developing an intrapreneurial culture. Also managers' specific leadership styles support the intrapreneurial behaviour of employees. Thus, middle-level managers' contribution to intrapreneurship within a firm is broad: from motivating employees to be innovative and think across organizational unit boundaries, to demonstrating opportunities to realize ideas, supporting intrapreneurial employees and serving as role models. Therefore, middle-level managers themselves should be characterized by entrepreneurial skills and innovative behaviour. Organizations should consider this when recruiting managers and developmental training should further develop these capabilities to exploit the huge potential residing in these managers.

Furthermore, organizations should also pay attention to developing the intrapreneurial skills of their employees. As research has shown, the perceived ability to engage in entrepreneurial behaviour is crucial for actually demonstrating entrepreneurial behaviour. To increase the perceived ability of employees, practising this behaviour and receiving feedback is important. The reciprocal connection between recognizing business opportunities, behaving entrepreneurially and receiving feedback affords an increase in the self-efficacy of employees. Organizations should therefore provide possibilities for learning and developing intrapreneurial skills. This enables employees to gain entrepreneurial experience within the safe setting of an existing organization and develop their intrapreneurial skills further.

As intrapreneurship in the academic context has gained in importance, research also provides recommendations for academia. The current challenges faced by universities, such as tightening budgets and intensive competition, are forcing academia to redefine strategic capabilities by developing an intrapreneurial and innovative mindset. Therefore, innovative and intrapreneurial staff at universities play a key role. The underlying motivation for these so-called academic intrapreneurs is the opportunity to use their acquired academic knowledge for a wider purpose than teaching and research. Hence they value the possibility of realizing ideas outside research and transfer the knowledge generated into new projects and above all new products or processes. University management should be aware of the high potential of academic intrapreneurs, as they are the ones leading academia in a new strategic direction and fostering "out-of-the-box" thinking 
within universities. To support academic intrapreneurs, researchers have underlined the importance of a clear orientation towards an entrepreneurial university, a universitywide model of entrepreneurship, an intrapreneurship-friendly culture and the rewarding of intrapreneurs. Universities should offer an environment suitable for idea exchange, experimenting, innovative projects, cooperation between institutes and relationships outside academia, e.g. with industry. Such an environment and simultaneously the safe setting of an established organization like a university could foster successful knowledge transfer by scientific staff in a way that is innovative and forward thinking.

\subsection{Limitations and implications for research}

The systematic literature review was carried out using five relevant databases in the entrepreneurship field. Based on the literature, specific search terms and inclusion criteria were identified. To ensure a quality threshold, VHB and AJG rankings were additional inclusion criteria. Despite these efforts to ensure a systematic approach, the review may not have included all research addressing intrapreneurship as books were not part of it. A further limitation arises from the individual-level focus of the review. To close the research gap concerning the individual-level perspective, a narrow focus on intrapreneurship had to be used. Hence the related concepts of corporate entrepreneurship and entrepreneurial orientation were excluded from the investigation. Furthermore, to present the state of research, only publications in journals in the thematic areas of entrepreneurship and innovation were included. Therefore, possibly relevant studies within other research fields were excluded.

In the course of the review, the sample articles were also investigated with regard to their research implications and suggestions for future research. With regard to the thematic orientation of intrapreneurship research, the authors in the sample mentioned in particular the use of combined models of organizational and individual factors and research improving and refining the measurement scales used. There was a clear call for research working on objective measurement scales of intrapreneurial personality, innovative behaviour and human capital. In addition to the authors' suggestions in the sample articles, future research should investigate the intrapreneurship concept in combination with the organizational-level concepts of corporate entrepreneurship and entrepreneurial orientation. Such a combined approach has been claimed for organizations' practice and research should also aim at working with combined models. This would provide a more holistic view that has thus far mostly been neglected. Furthermore, research should include other perspectives. Studies should investigate the influence of team-level factors on the intrapreneurial behaviour of employees. In this review the team-level perspective was excluded and research in this area is rare. Nevertheless, it can be argued that the team-level perspective also provides interesting insights into intrapreneurial behaviour within firms, as topics such as networks and relationships between employees and different organizational departments can play a crucial role for innovation processes and intrapreneurship projects. A combined approach rooted in organizational and individual concepts and the integration of various analytical levels would be an important step towards developing a holistic view of intrapreneurship. 
Another suggestion for future research, also indicated in the sample articles, is a focus on possible external factors influencing intrapreneurial behaviour. While research has recognized the various possible contexts of intrapreneurship, there is a lack of attention paid to national factors concerning environment and culture. As intrapreneurship is rooted in entrepreneurial values, behavioural components (e.g. attitudes) and also social capital, research focusing on the influence of the environment and cultural differences would be interesting. In particular, the issue of cultural factors as moderating variables is of considerable importance and would offer insights into whether and what role culture might play in fostering intrapreneurial behaviour.

In addition, there are research implications in terms of methodology. As the review sample showed, research conducted in the field of intrapreneurship has developed over time, from a few articles that were qualitative and conceptual in nature to articles using mostly quantitative research methods. The review provided in this paper gives an overview of the field, but to gain deeper insights into intrapreneurial behaviour and the individual intrapreneur, other methods are needed. Researchers have pointed to the need for longitudinal studies in intrapreneurship research. The use of longitudinal studies should be the subject of future research as they promise detailed knowledge of the intrapreneurship concept. Furthermore, longitudinal research would allow insights into intrapreneurial activities and their impact on organizational performance, a research area under-represented in existing studies. In particular, intrapreneurs' behaviours leading to strategic renewal "require a considerable amount of time to exert their full effect" (Bierwerth et al. 2015, p. 273.), a long-term benefit of intrapreneurship not measureable with cross-sectional research designs. Based on the proposition of Rigtering and Weitzel (2013), intrapreneurship can be viewed as a two-step-process: first employees are stimulated to develop intrapreneurial skills and behaviour and afterwards are involved in intrapreneurship projects. Hence, future research should consider how intrapreneurial experience is gained and the role of the support of managers, management processes and organizational settings in changing employees' entrepreneurial self-efficacy and thus intrapreneurial behaviour over time.

Acknowledgements Open access funding provided by Johannes Kepler University Linz. The author thanks the participants of the 13th European Summer University Conference (ESU Conference 2016) of the European University Network on Entrepreneurship in Lyon (France) for valuable comments on an earlier version of this paper.

\section{Compliance with ethical standards}

Conflict of interest The author declares that she has no conflict of interest.

Open Access This article is distributed under the terms of the Creative Commons Attribution 4.0 International License (http://creativecommons.org/licenses/by/4.0/), which permits unrestricted use, distribution, and reproduction in any medium, provided you give appropriate credit to the original author(s) and the source, provide a link to the Creative Commons license, and indicate if changes were made.

\section{Appendix}

See Tables 2 and 3. 


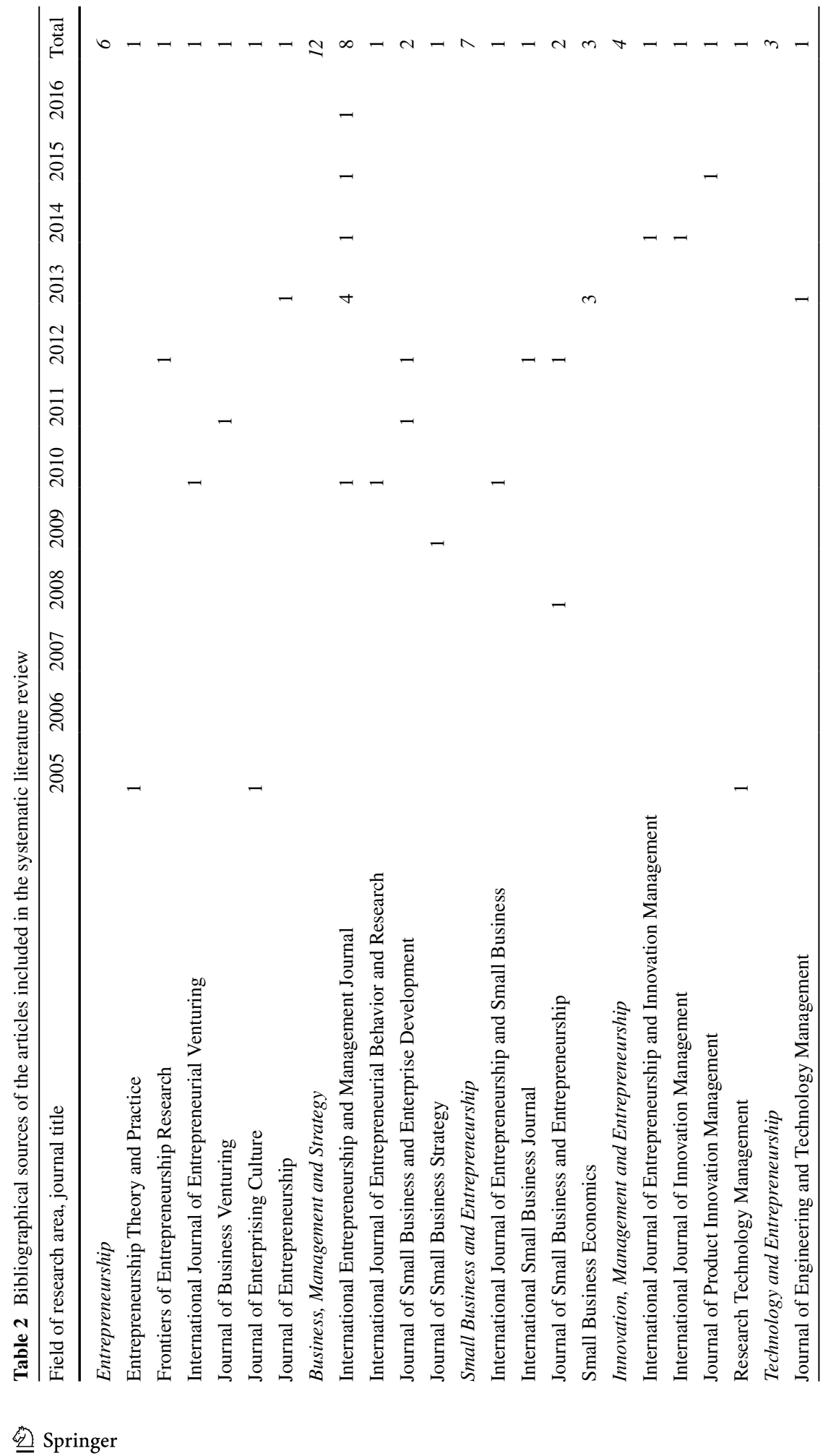




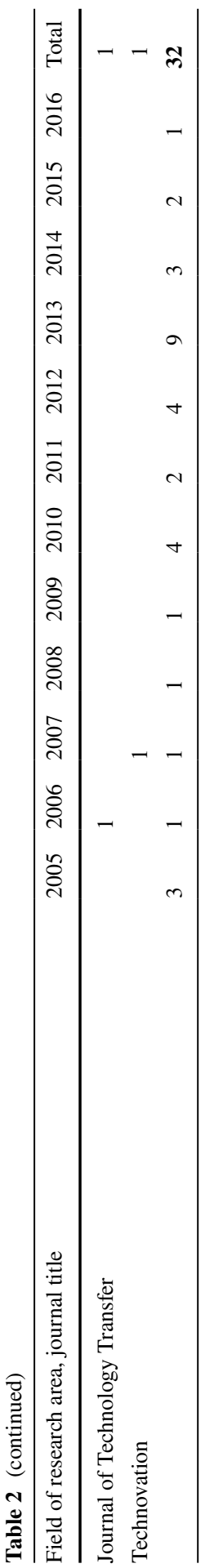




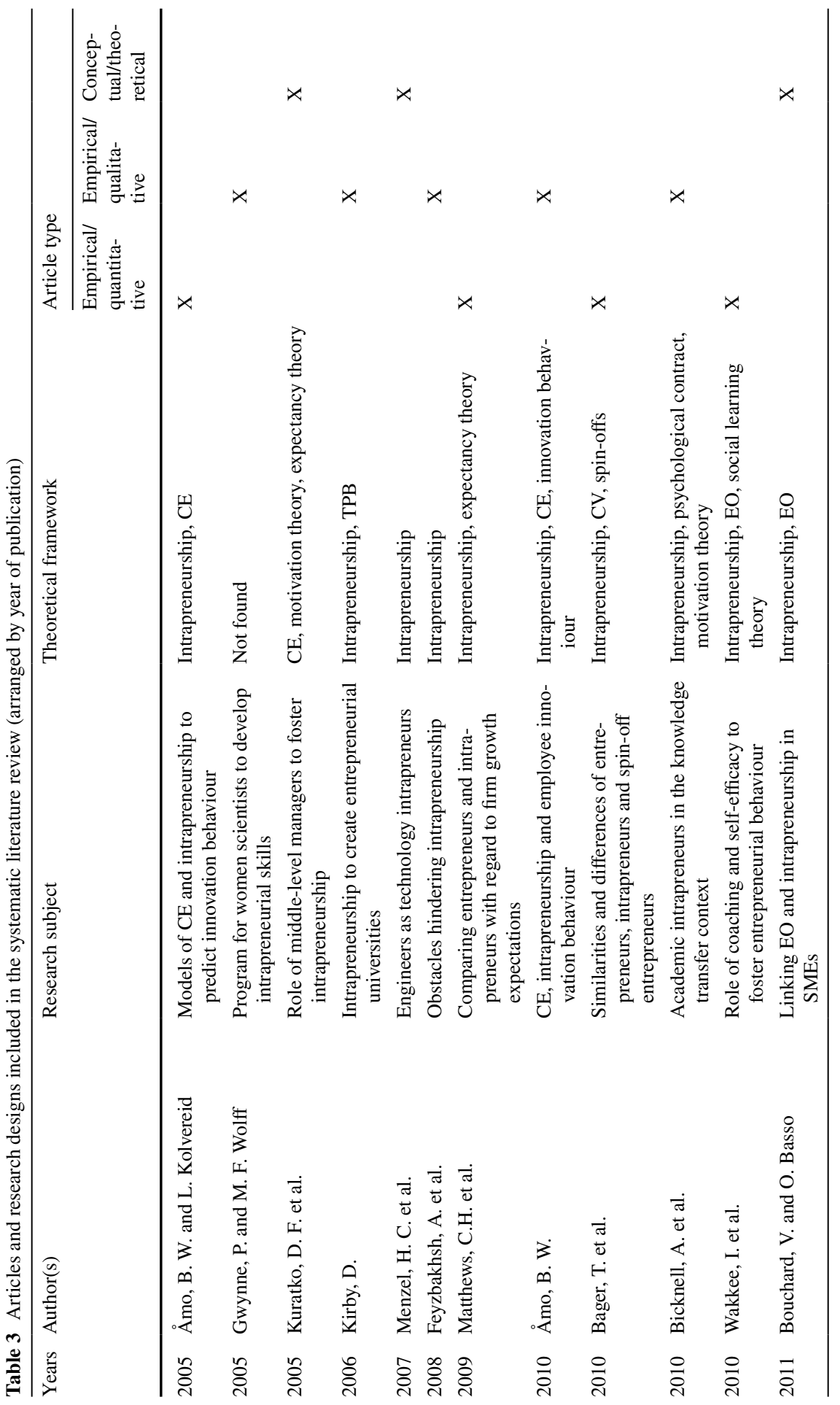




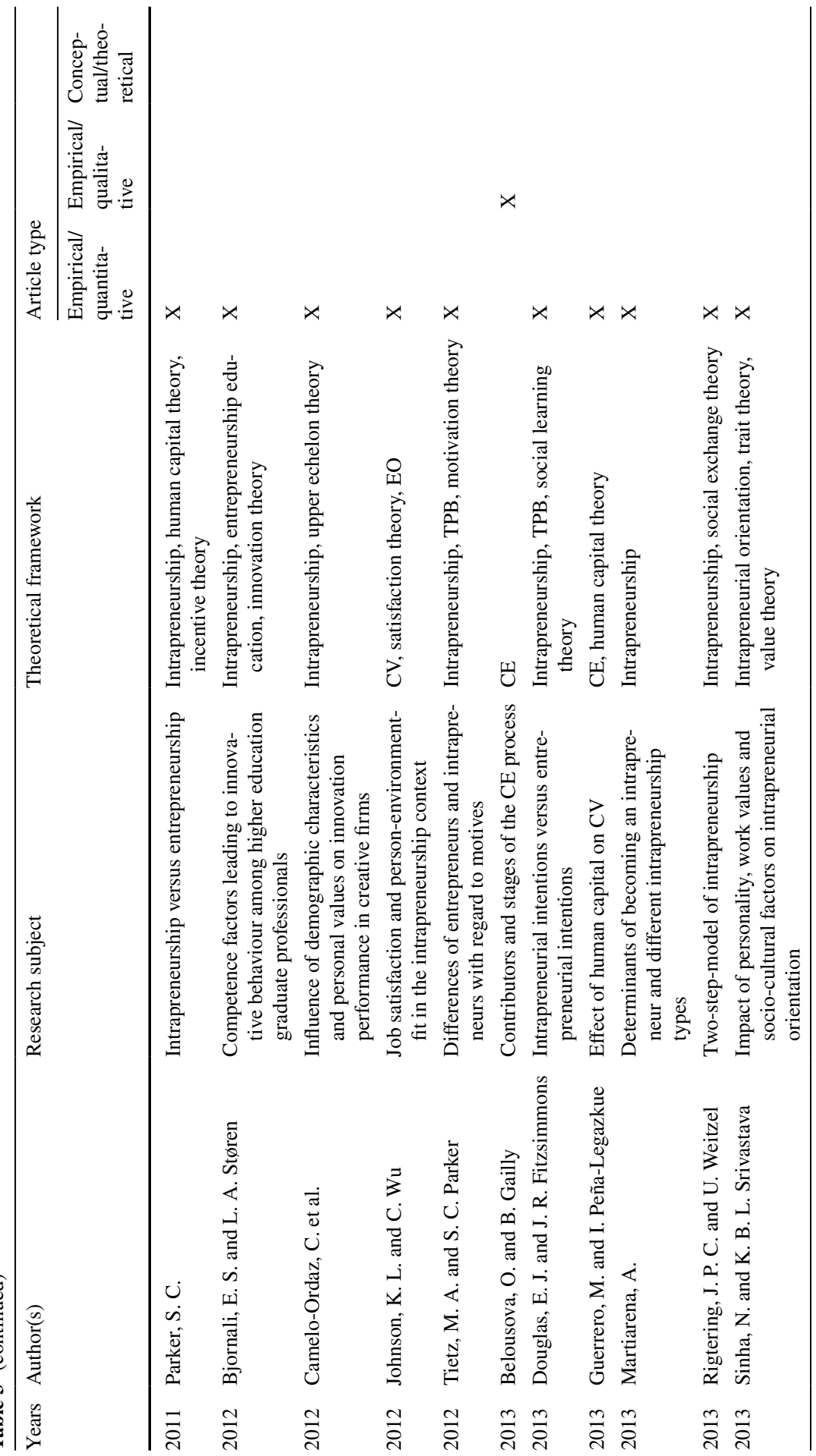



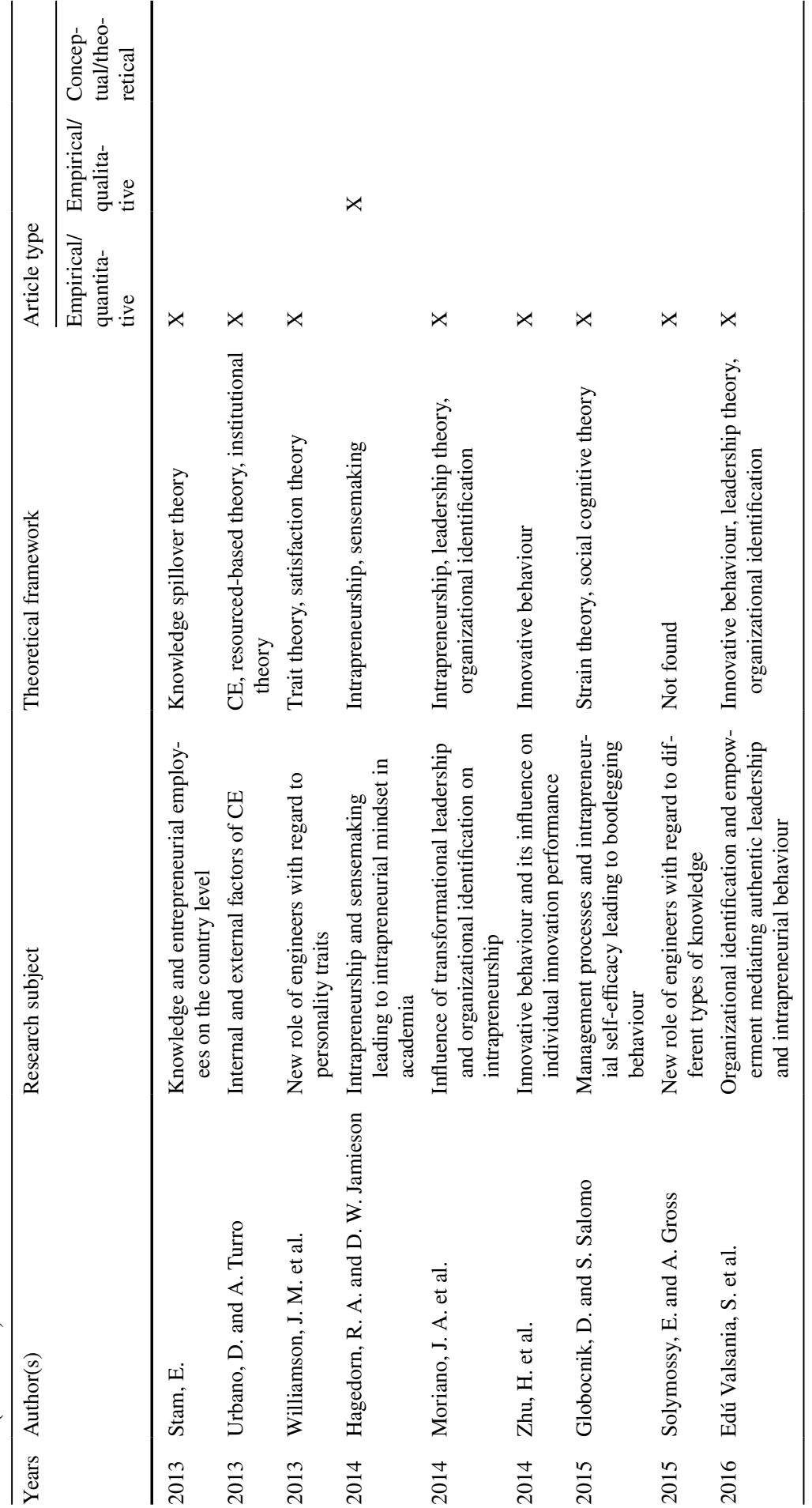


\section{References}

Ajzen I (1985) From intentions to actions: a theory of planned behavior. In: Kuhl J, Beckmann J (eds) Action control-from cognition to behavior. Springer, Heidelberg, pp 11-39

Ajzen I (1991) The theory of planned behavior. Organ Behav Hum Dec 50:179-211. https://doi. org/10.1016/0749-5978(91)90020-t

Åmo BW (2010) Corporate entrepreneurship and intrapreneurship related to innovation behaviour among employees. Int J Entrep Ventur 2:144-158. https://doi.org/10.1504/ijev.2010.034819

Åmo BW, Kolvereid L (2005) Organizational strategy, individual personality and innovation behavior. J Enterp Cult 13:7-19

Anderson BS, Covin JG (2014) Entrepreneurial orientation: disposition and behavior. In: Fayolle A (ed) Handbook of research an entrepreneurship: what we know and what we need to know. Edward Elgar Publishing, Cheltenham (UK), Northampton, pp 215-237

Antoncic B, Hisrich RD (2003) Clarifying the intrapreneurship concept. J Small Bus Enterp Dev 10:7-24

Bager T, Ottósson H, Schott T (2010) Intrapreneurs, entrepreneurs and spin-off entrepreneurs: similarities and differences. Int J Entrep Small Bus 10:339-358. https://doi.org/10.1504/ijesb.2010.033572

Bandura A (1977) Self-efficacy: toward a unifying theory of behavioral change. Psychol Rev 84:191-215

Bandura A (1986) Social foundations of thought and action: a social cognitive theory. Prentice Hall, Englewood Cliffs

Baruah B, Ward A (2015) Metamorphosis of intrapreneurship as an effective organizational strategy. Int Entrep Manag J 11:811-822. https://doi.org/10.1007/s11365-014-0318-3

Belousova O, Gailly B (2013) Corporate entrepreneurship in a dispersed setting: actors, behaviors, and process. Int Entrep Manag J 9:361-377. https://doi.org/10.1007/s11365-013-0259-2

Bicknell A, Francis-Smythe J, Arthur J (2010) Knowledge transfer: de-constructing the entrepreneurial academic. Int J Entrep Behav Res 16:485-501. https://doi.org/10.1108/13552551011082461

Bierwerth M, Schwens C, Isidor R, Kabst R (2015) Corporate entrepreneurship and performance: a metaanalysis. Small Bus Econ 45:255-278

Bjornali ES, Støren LA (2012) Examining competence factors that encourage innovative behaviour by European higher education graduate professionals. J Small Bus Enterp Dev 19:402-423. https://doi. org/10.1108/14626001211250135

Bouchard V, Basso O (2011) Exploring the links between entrepreneurial orientation and intrapreneurship in SMEs. J Small Bus Enterp Dev 18:219-231. https://doi.org/10.1108/14626001111127043

Camelo-Ordaz C, Fernandez-Alles M, Ruiz-Navarro J, Sousa-Ginel E (2012) The intrapreneur and innovation in creative firms. Int Small Bus J 30:513-535. https://doi.org/10.1177/0266242610385396

Christensen KS (2005) Enabling intrapreneurship: the case of a knowledge-intensive industrial company. Eur J Innov Manag 8:305-322. https://doi.org/10.1108/14601060510610171

Coleman JS (1988) Social capital in the creation of human-capital. Am J Sociol 94:95-120. https://doi. org/10.1086/228943

Covin JG, Slevin DP (1991) A conceptual model of entrepreneurship as firm behavior. Entrep Theory Pract 16:7-25

Covin JG, Wales WJ (2012) The measurement of entrepreneurial orientation. Entrep Theory Pract 36:677-702. https://doi.org/10.1111/j.1540-6520.2010.00432.x

Creswell JW (2009) Research design-qualitative, quantitative and mixed methods approaches. Sage, London

Dess GG, Ireland RD, Zahara SA, Floyd SW, Janney JJ, Lane PJ (2003) Emerging issues in corporate entrepreneurship. J Manag 29:351-378. https://doi.org/10.1016/s0149-2063(03)00015-1

Dobrow SR, Chandler DE, Murphy WM, Kram KE (2012) A review of developmental networks: incorporating a mutuality perspective. J Manag 38:210-242

Douglas EJ, Fitzsimmons JR (2013) Intrapreneurial intentions versus entrepreneurial intentions: distinct constructs with different antecedents. Small Bus Econ 41:115-132. https://doi.org/10.1007/s1118 7-012-9419-y

Edú Valsania S, Moriano JA, Molero F (2016) Authentic leadership and intrapreneurial behavior: crosslevel analysis of the mediator effect of organizational identification and empowerment. Int Entrep Manag J 12:131-152. https://doi.org/10.1007/s11365-014-0333-4

Feyzbakhsh AS, Sadeghi R, Shoraka S (2008) A case study of intrapreneurship obstacles: the RAJA passenger train company. J Small Bus Entrep 21:171-180 
Gapp R, Fisher R (2007) Developing an intrapreneur-led three-phase model of innovation. Int J Entrep Behav Res 13:330-348. https://doi.org/10.1108/13552550710829151

Globocnik D, Salomo S (2015) Do formal management practices impact the emergence of bootlegging behavior? J Prod Innov Manag 32:505-521. https://doi.org/10.1111/jpim.12215

Granovetter MS (1973) The strength of weak ties. Am J Sociol 78:1360-1380. https://doi.org/10.1086/ 225469

Guerrero M, Peña-Legazkue I (2013) The effect of intrapreneurial experience on corporate venturing: evidence from developed economies. Int Entrep Manag J 9:397-416. https://doi.org/10.1007/s1136 5-013-0260-9

Gwynne P, Wolff MF (2005) Introducing women to intrapreneurial thinking. Res Technol Manag 48:4-5

Hagedorn RA, Jamieson DW (2014) Intrapreneurial sensemaking: the case of a reenvisioned school of professional studies. Int J Entrep Innov Manag 18:425-437. https://doi.org/10.1504/ijeim .2014 .064715

Higgins MC, Kram KE (2001) Reconceptualizing mentoring at work: a developmental network perspective. Acad Manag Rev 26:264-288. https://doi.org/10.2307/259122

Iacobucci D, Rosa P (2010) The growth of business groups by habitual entrepreneurs: the role of entrepreneurial teams. Entrep Theory Pract 34:351-377. https://doi.org/10.1111/j.1540-6520.2010.00378 .X

Ireland RD, Covin JG, Kuratko DF (2009) Conceptualizing corporate entrepreneurship strategy. Entrep Theory Pract 33:19-46. https://doi.org/10.1111/j.1540-6520.2008.00279.x

Jesson JK, Matheson L, Lacey FM (2011) Doing your literature review-traditional and systematic techniques. Sage, London

Johnson KL, Wu C (2012) Creating entrepreneurial opportunities as a means to maintain entrepreneurial talent in corporations. J Small Bus Entrep 25:327-348

Kanter RM (1984) The change masters. Simon and Schuster, New York

Kirby D (2006) Creating entrepreneurial universities in the UK: applying entrepreneurship theory to practice. J Technol Transf 31:599-603. https://doi.org/10.1007/s10961-006-9061-4

Kuratko DF, Audretsch DB (2013) Clarifying the domains of corporate entrepreneurship. Int Entrep Manag J 9:323-335. https://doi.org/10.1007/s11365-013-0257-4

Kuratko DF, Ireland RD, Covin JG, Hornsby JS (2005) A model of middle-level managers' entrepreneurial behavior. Entrep Theory Pract 29:699-716. https://doi.org/10.1111/j.1540-6520.2005.00104.x

Lumpkin GT, Dess GG (1996) Clarifying the entrepreneurial orientation construct and linking it to performance. Acad Manag J 21:135-172

Martiarena A (2013) What's so entrepreneurial about intrapreneurs? Small Bus Econ 40:27-39. https:// doi.org/10.1007/s11187-011-9348-1

Matthews CH, Schenkel MT, Ford MW, Human SE (2009) Comparing nascent entrepreneurs and intrapreneurs and expectations of firm growth. J Small Bus Strategy 20:53-80

Menzel HC, Aaltio I, Ulijn JM (2007) On the way to creativity: engineers as intrapreneurs in organizations. Technovation 27:732-743. https://doi.org/10.1016/j.technovation.2007.05.004

Miller D (1983) The correlates of entrepreneurship in three types of firms. Manag Sci 29:770-791

Moriano JA, Molero F, Topa G, Lévy Mangin J-P (2014) The influence of transformational leadership and organizational identification on intrapreneurship. Int Entrep Manag J 10:103-119. https://doi. org/10.1007/s11365-011-0196-x

Parker SC (2011) Intrapreneurship or entrepreneurship? J Bus Venturing 26:19-34. https://doi. org/10.1016/j.jbusvent.2009.07.003

Pinchot G (1985) Intrapreneuring: why you don't have to leave the corporation to become an entrepreneur. Harper \& Row, New York

Pinchot G, Pellman R (1999) Intrapreneuring in action: a handbook of business innovation. Berrett-Koehler Publishers Inc., San Francisco

Rigtering JPC, Weitzel U (2013) Work context and employee behaviour as antecedents for intrapreneurship. Int Entrep Manag J 9:337-360. https://doi.org/10.1007/s11365-013-0258-3

Sinha N, Srivastava KBL (2013) Association of personality, work values and socio-cultural factors with intrapreneurial orientation. J Entrep 22:97-113

Solymossy E, Gross A (2015) Taking the engineering path to business leadership and entrepreneurial success in Canada and USA. Int Entrep Manag J 11:393-408. https://doi.org/10.1007/s1136 5-014-0298-3

Stam E (2013) Knowledge and entrepreneurial employees: a country-level analysis. Small Bus Econ 41:887-898. https://doi.org/10.1007/s11187-013-9511-y 
Tietz MA, Parker SC (2012) How do intrapreneurs and entrepreneurs differ in their motivation to start a new venture? Front Entrep Res 32:146-160

Tranfield D, Denyer D, Smart P (2003) Towards a methodology for developing evidence-informed management knowledge by means of systematic review. Br J Manag 14:207-222

Turro A, Alvarez C, Urbano D (2016) Intrapreneurship in the spanish context: a regional analysis. Entrep Reg Dev 28:380-402

Urbano D, Turro A (2013) Conditioning factors for corporate entrepreneurship: an in(ex)ternal approach. Int Entrep Manag J 9:379-396. https://doi.org/10.1007/s11365-013-0261-8

Veenker S, Pvd Sijde, During W, Nijhof A (2008) Organisational conditions for corporate entrepreneurship in Dutch organisations. J Entrep 17:49-58. https://doi.org/10.1177/097135570701700104

Wakkee I, Elfring T, Monaghan S (2010) Creating entrepreneurial employees in traditional service sectors the role of coaching and self-efficacy. Int Entrep Manag J 6:1-21. https://doi.org/10.1007/s1136 5-008-0078-Z

Wales WJ (2015) Entrepreneurial orientation: a review and synthesis of promising research directions. Int Small Bus J 34:3-15

Williamson JM, Lounsbury JW, Han LD (2013) Key personality traits of engineers for innovation and technology development. J Eng Tech Manage 30:157-168. https://doi.org/10.1016/j.jengtecman .2013.01.003

Zhu H, Djurjagina K, Leker J (2014) Innovative behaviour types and their influence on individual crowdsourcing performances. Int J Innov Manag 18:1440015. https://doi.org/10.1142/s13639196144001 55

Zomer A, Benneworth P (2011) The rise of the university's third mission. In: Enders J, de Boer HF, Westerheijden DF (eds) Reform of higher education in Europe. Sense Publishers, Rotterdam, pp 81-101 